\title{
rDNA insulin glargine U300 - a critical appraisal
}

This article was published in the following Dove Press journal:

Diabetes, Metabolic Syndrome and Obesity:Targets and Therapy

2 December 2016

Number of times this article has been viewed

\section{Fei Wang'}

Stefanie Zassman'

Philip A Goldberg²

'Department of Pharmacy Practice, School of Pharmacy, University of Connecticut, Storrs, CT, USA; ${ }^{2}$ Department of Internal Medicine, Section of Endocrinology, Yale University School of Medicine, New Haven, CT, USA
Correspondence: Fei Wang Department of Pharmacy Practice, School of Pharmacy, University of Connecticut, 69 North Eagleville Road, Unit 3092, Storrs, CT 06269, USA

Tel +l 8609724 125

Email fei.wang@uconn.edu
Background: As the first once-daily basal insulin analog, insulin glargine $100 \mathrm{U} / \mathrm{mL}$ (Gla-100; Lantus $^{\circledR}$ ) rapidly evolved into the most commonly prescribed insulin therapy worldwide. However, this insulin has clinical limitations. The approval of new basal insulin analogs in 2015 has already started to alter the prescribing landscape.

Objective: To review the available evidence on the clinical efficacy and safety of a more concentrated insulin glargine (recombinant DNA origin) injection $300 \mathrm{U} / \mathrm{mL}$ (Gla-300) compared to insulin Gla-100 in patients with type 1 and type 2 diabetes mellitus (T1DM and T2DM).

Methods: The following electronic databases were searched: PubMed and MEDLINE (using Ovid platform), Scopus, BIOSIS, and Google Scholar through June 2016. Conference proceedings of the American Diabetes Association (2015-2016) were reviewed. We also manually searched reference lists of pertinent reviews and trials.

Results: A total of 6 pivotal Phase III randomized controlled trials known as the EDITION series were reviewed. All of these trials $(n=3,500)$ were head-to-head comparisons evaluating the efficacy and tolerability of Gla-300 vs Gla-100 in a diverse population with T1DM and T2DM. These trials were of 6 months duration with a 6-month safety extension phase.

Conclusion: Gla-300 was as effective as Gla-100 for improving glycemic control over 6 months in all studies, with a lower risk of nocturnal hypoglycemia significant only in insulin-experienced patients with T2DM. Overall, patients on Gla-300 required $10 \%-18 \%$ more basal insulin, but with less weight gain compared with Gla-100.

Keywords: basal insulin, glargine $300 \mathrm{U} / \mathrm{mL}$, glargine $100 \mathrm{U} / \mathrm{mL}$

\section{Introduction}

Insulin glargine, synthesized by recombinant DNA technology (rDNA) in a concentration of $100 \mathrm{U} / \mathrm{mL}$ (insulin glargine $100 \mathrm{U} / \mathrm{mL}$ [Gla-100]; Lantus ${ }^{\circledR}$ [or Optisulin ${ }^{\circledR}$ in the EU]; Sanofi-Aventis, Paris, France) was the first once-daily basal insulin analog to be introduced into clinical practice in 2000. ${ }^{1}$ It has a well-established record of efficacy and safety and is the most widely used basal insulin worldwide. ${ }^{2-4}$ However, Gla-100 lost its US patent protection in February 2015, which opened the door for biosimilar competitors. ${ }^{5,6}$ In addition, new long-acting basal insulin formulations have entered the United States and global marketplace. ${ }^{7}$

Basal insulin secretion is essential for the maintenance of fasting glucose levels, especially through inhibition of excessive hepatic glucose output. The aim of basal insulin replacement is to provide consistent insulin levels between meals, thereby minimizing the risk of hypoglycemia, particularly at night. The ideal basal insulin would provide a flat, peakless glucose-lowering profile, and would have a protracted 
duration of action of more than 24 hours to enable oncedaily dosing. The introduction of rDNA technology (rDNA origin) has enabled the optimization of the properties of human insulin via modification of the amino acid sequence to provide soluble insulin analogs that better mimic physiologic insulin secretion. ${ }^{8}$

The long-acting recombinant basal insulin analogs were developed to overcome some of the limitations of early intermediate-acting basal insulin complexed with protamine (neutral protamine Hagedorn $[\mathrm{NPH}]$ insulin). ${ }^{9,10}$ Established long-acting basal insulin analogs, glargine and detemir (both available as $\mathrm{U} 100$ insulin or $100 \mathrm{U} / \mathrm{mL}$ ), were modified to delay their absorption, providing more prolonged and stable pharmacokinetic and pharmacodynamic characteristics compared to NPH insulin. The major benefits of these basal insulin analogs included: 1) a reduction in clinically important rates of hypoglycemia (including nocturnal and severe hypoglycemia), 2) a protracted duration of action, permitting once-daily dosing, and 3) lower within- and between-subject variability, leading to more consistent and predictable glycemic control. ${ }^{2,9,10}$

Although no clinically relevant differences in efficacy or safety between glargine and detemir have been established in patients with type 1 or 2 diabetes mellitus (T1DM or T2DM), the available evidence suggests that higher doses of detemir as compared with Gla-100 may be needed to achieve the same glycemic control. ${ }^{11-14}$ Additionally, detemir sometimes requires twice-daily injections to achieve similar glycemic control, but with less weight gain compared to Gla-100. ${ }^{13,14}$ On the basis of these findings, Gla-100 is almost always prescribed as a once-daily basal insulin, whereas detemir is sometimes dosed twice daily.

Despite the fact that many limitations of NPH insulin were addressed by Gla-100 and detemir, in clinical practice these insulin analogs sometimes do not consistently provide a full 24-hour duration of action. ${ }^{15}$ As a result, nocturnal hypoglycemia can still occur when basal insulin doses are raised to improve fasting hyperglycemia. ${ }^{2}$ Additionally, in patients with insulin resistance who require high doses of insulin, it is not always possible to satisfy the dose requirement without injecting large volumes. As existing insulin pens are limited to a maximum delivery of 80 units of insulin in one injection, this has often necessitated two daily injections of Glar-100 or detemir. ${ }^{11,12}$ When large volumes of insulin are injected at one site, the absorption is also likely to be erratic and the effect less predictable. ${ }^{16}$

In this setting, novel formulations of basal insulin analogs were developed to provide more consistent insulin profiles, with more protracted durations of action beyond 24 hours. Additionally, further refinement of concentrated formulations of basal insulin analogs was intended to better address insulin resistance and high injection volumes. Recent pharma innovations include insulin degludec (Tresiba, Novo Nordisk), an ultralong-acting insulin with a duration of action $>42$ hours, ${ }^{17-19}$ and several insulin glargine products including the biosimilar insulin, Basaglar (Abasaglar in Europe $)^{6,20}$ and high-strength insulin glargine U300, a highly concentrated form of insulin glargine that delivers 300 units of insulin per $1 \mathrm{~mL}$ of solution (one-third of the volume). ${ }^{21,22}$ Development of the basal insulin peglispro, another long-acting insulin analog in Phase III trials that showed promise, was discontinued in 2015 due to signals of liver injury related to fat accumulation. ${ }^{23}$ This review provides an overview comparing the clinical efficacy, safety, and tolerability data of Gla-300 (insulin glargine $300 \mathrm{U} / \mathrm{mL}$ ) relative to Gla- 100 .

\section{Methods}

The following electronic databases were searched: PubMed and MEDLINE (using Ovid platform), Scopus, BIOSIS, and Google Scholar through June 2016. Conference proceedings of the American Diabetes Association (ADA; 2015-2016) were reviewed. We also manually searched reference lists of pertinent reviews and trials. When an abstract from a meeting and a full article referred to the same trial, only the full publication was included in the analysis.

\section{Glargine $300 \mathrm{U} / \mathrm{mL}$ (Gla-300)}

Gla-300 is approved for use in adult patients ( $>18$ years) with T1DM and T2DM. It was licensed in the United States, Europe, and Japan in 2015 (as Toujeo ${ }^{\circledR}$ in the United States and Europe; as Lantus ${ }^{\circledR}$ XR in Japan [Sanofi-Aventis]). ${ }^{24-26}$

\section{Pharmacology}

Insulin Gla-100 is produced by rDNA technology utilizing a nonpathogenic laboratory strain of Escherichia coli as the production organism. It differs structurally from human insulin by the addition of two arginine molecules after position B30 and the replacement of asparagine with glycine at position $\mathrm{A} 21 .^{27,28}$ This modification allows it to remain soluble within the acidic $\mathrm{pH}$ of the injection medium; the molecule then becomes less soluble at the $\mathrm{pH}$ of physiologic tissue. After subcutaneous injection, the acidic solution is neutralized at physiological $\mathrm{pH}$. This leads to the formation of a microprecipitate within the subcutaneous depot, from which insulin glargine is slowly released. ${ }^{27}$ 
The glargine molecule remains unchanged in Gla-300. Gla-300 has an identical amino acid sequence to Gla-100 and shares the same active metabolites (MI and M2). ${ }^{29}$ However, Gla-300 allows the formation of a more compact subcutaneous depot with a smaller surface area (generating a longer subcutaneous residence time with exposure to tissue peptidases), leading to a reduced redissolution rate following subcutaneous injection. ${ }^{30}$ This produces a more level activity profile and a more gradual and prolonged insulin release compared with Gla-100.21,31

\section{Pharmacokinetics (PK) and pharmacodynamics (PD)}

Several single-dose euglycemic clamp studies comparing Gla-300 with Gla-100 in both European and Japanese populations with T1DM $(n=96)$ evaluating different doses of Gla-300 (0.4, 0.6, and $0.9 \mathrm{U} / \mathrm{kg})$ and Gla-100 $(0.4 \mathrm{U} / \mathrm{kg})$ demonstrated that Gla-300 provided a flatter PK/PD profile over 24 hours, with a prolonged activity up to 36 hours (with doses $\geq 0.6 \mathrm{U} / \mathrm{kg}$ ) compared with Gla-100.22,31,32

The data was confirmed in several euglycemic clamp studies with a similar study design provided under steadystate conditions, which is a better reflection of real life than a single-dose design. ${ }^{21,29,33,34}$ At steady state, Gla-300 has a more stable and prolonged PK/PD profile than Gla-100, with a half-life of 18-19 hours (independent of dose), and a prolonged duration of glucose-lowering activity exceeding 24 hours (up to 36 hours). ${ }^{21}$ This activity is more constant and evenly distributed with Gla-300 than Gla-100, with low within-subject variability and high day-to-day reproducibility. ${ }^{33}$ These characteristics could potentially lead to a reduced risk of hypoglycemia with Gla-300 compared with Gla-100. Once-daily injections of Gla-300 may take up to 3-5 days to reach steady state, suggesting that dose adjustments with Gla-300 should be addressed within a week of treatment initiation. ${ }^{21,29}$ There is no further accumulation of its predominant active metabolite (M1) on repeat administration of Gla-300 once a day with an interval of 24 hours between injections, ${ }^{35,36}$ and the active metabolites have a lower affinity for insulin-like growth factor 1 receptor compared with human insulin. ${ }^{29}$ Overall, there is a lack of PK data on the effects of Gla-300 in renal or hepatic impairment or in the elderly population. ${ }^{25}$

\section{Phase III clinical trials}

The clinical efficacy and safety of Gla-300 compared with that of Gla-100 were evaluated in 3,500 people with diabetes in a global (North America, Europe, South Africa, and
Japan) series of six pivotal Phase III studies known as the EDITION series, supported by the drug sponsor. ${ }^{24,30,37-40}$ These were multicenter, randomized, open-label, parallelgroup trials with similar study design and outcomes. (The open-label design was due to differences in the pen injector devices and volumes in the Gla-300 and Gla-100 treatment groups.)

EDITION 1, 2, and 3 were conducted in patients with T2DM, ${ }^{30,37,38}$ while EDITION 4 was conducted in patients with T1DM. ${ }^{39}$ EDITION JP $1^{40}$ and JP $2^{24}$ were conducted in Japanese patients with T1DM and T2DM, respectively (Table 1).

The EDITION series in T2DM included a diverse multinational population of patients who were either insulin experienced or -naive. Subjects in the EDITION 1, 2, and JP 2 studies were already receiving basal insulin, either with mealtime insulin (EDITION 1) $)^{30}$ or oral antidiabetes drugs (OADs; EDITION 2 and JP 2);24,37 EDITION 3 was conducted in insulin-naive patients uncontrolled on OADs.$^{38}$ EDITION 4 and EDITION JP 1 were conducted in subjects with T1DM on mealtime insulin plus either Gla-300 or Gla-100 once daily $^{39,40}$ (Table 1).

All the individual EDITION trials were head-to-head studies of Gla-300 vs Gla-100 of 6-month treatment duration, with a preplanned 6-month safety extension phase. . $4,30,37,38,40^{-1}$ Extension studies to 12 months have been completed and published for EDITION 1 and EDITION 2, ${ }^{41,42}$ and these data are available as abstracts in two other studies conducted in a Japanese population $^{43,44}$ (Tables 2 and 3).

Six-month ${ }^{45}$ and 1 -year ${ }^{46}$ post hoc head-to-head comparisons of Gla-300 vs Gla-100 pooled from three randomized controlled trials (RCTs; EDITION 1, 2, and 3) in T2DM (Table 3), and an indirect head-to-head analysis comparing the efficacy and safety of Gla-300 vs other basal insulin therapies for the treatment of T2DM (that included Gla-100, biosimilar glargine, detemir, degludec, NPH, and premixed insulin) has become available. ${ }^{47}$

\section{Outcomes}

The EDITION studies were designed as noninferiority trials vs Gla-100, with a primary end point of change in glycated hemoglobin $\left(\mathrm{HbA}_{1 \mathrm{c}}\right)$ from baseline to month 6. Noninferiority was demonstrated if the upper limit of the $95 \%$ confidence interval (CI) for the mean difference in $\mathrm{HbA}_{1 \mathrm{c}}$ between Gla-300 and Gla-100 was $<0.4 \%$. Participants in all studies were randomized to receive once-daily subcutaneous injections of either Gla-300 or Gla-100 adjusted once weekly (based on the median of the last 3 fasting prebreakfast 
Table I Summary of baseline characteristics for individual studies

\begin{tabular}{|c|c|c|c|c|c|c|c|c|}
\hline \multirow[t]{2}{*}{ Study } & \multirow{2}{*}{$\begin{array}{l}\text { Background } \\
\text { regimen }\end{array}$} & \multirow[t]{2}{*}{ Comparators } & \multicolumn{6}{|c|}{ Mean baseline values } \\
\hline & & & $\begin{array}{l}\text { Age } \\
\text { (years) }\end{array}$ & $\begin{array}{l}\text { Duration of } \\
\text { diabetes (years) }\end{array}$ & BMI $\left(\mathbf{k g} / \mathrm{m}^{2}\right)$ & Weight (kg) & $\mathrm{HbA}_{\mathrm{Ic}}(\%)$ & $\begin{array}{l}\text { FPG } \\
(\mathrm{mg} / \mathrm{dL})\end{array}$ \\
\hline \multicolumn{9}{|l|}{ T2DM } \\
\hline EDITION I & Basal insulin + & Gla-300 & 60.1 & 15.6 & 36.6 & 106.2 & 8.15 & 158.3 \\
\hline$\left(\right.$ Riddle et $\mathrm{al}^{30}$ ) & mealtime insulin & Gla- 100 & 59.8 & 16.1 & 36.6 & 106.4 & 8.16 & 160.7 \\
\hline 6 month & & All & 60.0 & 16.0 & 36.6 & 106.3 & 8.15 & 160.0 \\
\hline EDITION 2 & Basal insulin + OAD & Gla-300 & 57.9 & 12.7 & 34.8 & 98.7 & 8.26 & 148.3 \\
\hline$\left(\right.$ Yki Jarvinen et $\mathrm{al}^{37}$ ) & & Gla- 100 & 58.5 & 12.5 & 34.8 & 98.0 & 8.22 & 142.0 \\
\hline 6 month & & All & 58.2 & 13.0 & 34.8 & 98.4 & 8.24 & 145.0 \\
\hline EDITION 3 & Insulin naïve $+O A D$ & Gla-300 & 58.2 & 10.1 & 32.8 & 95.1 & 8.49 & 178.7 \\
\hline$\left(\right.$ Bolli et $\mathrm{al}^{38}$ ) & & Gla- 100 & 57.2 & 9.6 & 33.2 & 95.6 & 8.58 & 183.8 \\
\hline 6 month & & All & 57.7 & 9.8 & 33.0 & 95.3 & 8.54 & 181.3 \\
\hline EDITION JP2 & Basal insulin + OAD & Gla-300 & 61.1 & 14.0 & 25.7 & 67.4 & 7.99 & 138.6 \\
\hline$\left(\right.$ Terauchi et $\mathrm{al}^{24}$ ) & & Gla-I00 & 60.5 & 13.9 & 24.8 & 65.9 & 8.06 & 133.2 \\
\hline 6 month & & All & 60.8 & 14.0 & 25.3 & 66.7 & 8.02 & 136.8 \\
\hline \multicolumn{9}{|l|}{ TIDM } \\
\hline EDITION 4 & Basal insulin + & Gla-300 & 46.4 & 20.5 & 27.6 & 81.9 & 8.11 & 185.9 \\
\hline$\left(\right.$ Home et $\mathrm{al}^{39}$ ) & mealtime insulin & Gla- 100 & 48.2 & 21.4 & 27.6 & 81.8 & 8.14 & 199.3 \\
\hline 6 month & & All & 47.3 & 20.9 & 27.6 & 81.9 & 8.13 & 192.6 \\
\hline EDITION JPI & Basal insulin + & Gla-300 & 44.1 & 12.2 & 23.8 & 63.9 & 8.06 & NR \\
\hline (Matsuhisa et $\mathrm{al}^{40}$ ) & mealtime insulin & Gla- 100 & 46.3 & 13.9 & 23.2 & 61.0 & 8.07 & NR \\
\hline 6 month & & All & 45.2 & 13.0 & 23.5 & 62.5 & 8.07 & NR \\
\hline
\end{tabular}

Abbreviations: $\mathrm{Gla}-100$, insulin glargine $100 \mathrm{U} / \mathrm{mL}$; Gla-300, insulin glargine $300 \mathrm{U} / \mathrm{mL} ; \mathrm{HbA}_{\mathrm{lc}}$, glycosylated hemoglobin; $\mathrm{FPG}$, fasting plasma glucose; OAD, oral antidiabetic drugs; TIDM, type I diabetes mellitus; T2DM, type 2 diabetes mellitus.

self-monitored plasma glucose [SMPGs] and not more than every 3 days), titrated to achieve a fasting SMPG target of $80-100 \mathrm{mg} / \mathrm{dL}(4.4-5.6 \mathrm{mmol} / \mathrm{L})$ in T2 $\mathrm{DM}^{24,30,37,38}$ or $80-130$ $\mathrm{mg} / \mathrm{dL}(4.4-7.2 \mathrm{mmol} / \mathrm{L})$ in T1DM. ${ }^{39,40}$ The main secondary efficacy end point was the percentage of participants with a composite category of at least one confirmed (blood glucose $\leq 70 \mathrm{mg} / \mathrm{dL}$ [ $\leq 3.9 \mathrm{mmol} / \mathrm{L}]$ ) or severe nocturnal hypoglycemic event (0000-0559 hours) reported between week 9 and month 6 in three of these $\mathrm{RCTs}^{30,37,38}$ and as a prespecified safety end point in all other studies. ${ }^{24,39,40}$
Other secondary efficacy end points included the following changes measured from baseline to month 6: laboratorymeasured fasting plasma glucose (FPG), percentage with $\mathrm{HbA}_{1 \mathrm{c}}<7 \%$ and $\mathrm{FPG} \leq 120 \mathrm{mg} / \mathrm{dL}(6.7 \mathrm{mmol} / \mathrm{L})$, average preinjection SMPG (measured before the time of basal insulin administration), variability of preinjection SMPG, mean and variability of 24-hour plasma glucose based on 8-point SMPG profiles, daily basal insulin dose, and body weight.

Primary and secondary efficacy end points were analyzed using a modified intention-to-treat analysis (defined

Table 2 Efficacy of Gla-300 vs Gla-100 in patients with TIDM

\begin{tabular}{|c|c|c|c|c|c|c|c|c|}
\hline \multirow[t]{2}{*}{ Study } & \multirow[t]{2}{*}{$\mathbf{N}$} & \multirow{2}{*}{$\begin{array}{l}\text { Duration } \\
\text { (months) }\end{array}$} & \multirow{2}{*}{$\begin{array}{l}\text { Background } \\
\text { regimen }\end{array}$} & \multirow[t]{2}{*}{ Comparators } & \multirow[t]{2}{*}{$\mathbf{N}$} & \multicolumn{3}{|c|}{ Mean change from baseline to end of study } \\
\hline & & & & & & $\mathrm{HbA}_{\mathrm{Ic}}(\%)$ & $\begin{array}{l}\text { Mean difference } \\
(95 \% \mathrm{Cl})^{\mathrm{a}}\end{array}$ & $\begin{array}{l}\text { FPG } \\
(\mathrm{mg} / \mathrm{dL})\end{array}$ \\
\hline EDITION 4 & 549 & 6 & Basal + mealtime & Gla-300 & 273 & -0.42 & $0.04(-0.10$ to 0.19$)$ & -17.1 \\
\hline$\left(\right.$ Home et $\left.\mathrm{al}^{39}\right)$ & & & insulin & Gla-I00 & 273 & -0.44 & & -20.5 \\
\hline EDITION JPI & 243 & 6 & Basal + mealtime & Gla-300 & 122 & -0.30 & $0.13(-0.03$ to 0.29$)$ & -13.4 \\
\hline (Matsuhisa et $\mathrm{al}^{40}$ ) & & & insulin & Gla-100 & 121 & -0.43 & & -20.8 \\
\hline EDITION JPI Ext & 228 & 12 & Basal + mealtime & Gla-300 & 114 & -0.20 & NR & -14.4 \\
\hline (Matsuhisa et $\mathrm{a}^{44}$ ) & & & Insulin & Gla-100 & 114 & -0.25 & & -7.2 \\
\hline
\end{tabular}

Notes: Measures of blood glucose control and insulin dose analyses based on modified intention-to-treat population. aLeast-square mean difference (except in JP I where this is reported as mean change [standard deviation]); banalyses based on safety population; 'statistically significant vs Gla- 100.

Abbreviations: TIDM, type I diabetes mellitus; $\mathrm{Cl}$, confidence interval; Ext, extension study; Gla- 100 , insulin glargine $100 \mathrm{U} / \mathrm{mL}$; $\mathrm{Gla}-300$, insulin glargine $300 \mathrm{U} / \mathrm{mL}$; $\mathrm{HbA}$, glycosylated hemoglobin; FPG, fasting plasma glucose; NR, not reported. 
as all randomized participants who received at least one dose of study insulin and had both a baseline and $\geq 1$ postbaseline assessment during the main 6-month treatment period)..$^{24,30,37,38,40}$ Change in body weight and (in some trials) hypoglycemia ${ }^{24,39,40}$ were analyzed using the safety population (the safety population included all participants randomized and exposed to $\geq 1$ dose of study treatment).

A summary of baseline characteristics from the individual study populations treated in the EDITION trials in both T1DM and T2DM patients is shown in Table 1. Changes in efficacy end points $\left(\mathrm{HbA}_{1 \mathrm{c}}, \mathrm{FPG}\right.$, body weight) from baseline to 6 and 12 months in T1DM and T2DM are presented in Tables 2 and 3, respectively. The incidence and rates of confirmed hypoglycemic events are described in Table 4.

\section{Type I diabetes (TIDM)}

The clinical efficacy and tolerability of Gla-300 compared to Gla-100 were evaluated in two Phase III clinical trials (EDITION 4 and JP 1) that enrolled a total of 792 patients with T1DM already on a stable dose of basal and mealtime insulin. The treatment regimen was once-daily Gla-300 or Gla-100 administered either in the evening (EDITION JP 1) or in the morning or evening (EDITION 4), while continuing mealtime insulin ${ }^{39,40}$ (Table 2). The population with T1DM in these trials was middle aged, with a duration of diabetes of 21.0 and 13.0 years, and a body mass index (BMI) of 28 and $24 \mathrm{~kg} / \mathrm{m}^{2}$, respectively, comparing the Japanese population in EDITION JP-1 to a multinational population in EDITION $4^{39,40}$ (Table 1).

\section{Glycemic control}

In EDITION $4(n=549)$ and EDITION JP-1 $(n=243)$, oncedaily Gla-300 was found to be noninferior to once-daily
Gla-100. A similar reduction in $\mathrm{HbA}_{1 \mathrm{c}}$ from baseline to month 6 was seen in both treatment groups, with a difference between groups of $0.04 \%$ (95\% CI: -0.10 to 0.19 ) and $0.13 \%$ (95\% CI: -0.03 to 0.29$)$, respectively. There was also no difference observed in glycemic control when Gla-300 was injected in the morning or evening. ${ }^{39}$ A similar percentage of people in each group achieved $\mathrm{HbA}_{1 \mathrm{c}}<7 \%$ at month 6 , $16 \%-17 \%$ for Gla-300 and $15 \%-20 \%$ for Gla- 100 , respectively (no statistical analysis reported). The average preinjection SMPG was significantly lower with Gla-300 vs Gla-100 at month 6, and otherwise other secondary end points were similar between the groups. ${ }^{39,40}$ In the Japanese extension study (baseline to month 12), glycemic control continued to be comparable between Gla-300 and Gla-100 (mean change in $\mathrm{HbA}_{1 \mathrm{c}}$ and FPG levels were $-0.20 \%$ and $-14 \mathrm{mg} / \mathrm{dL}$ compared to $-0.25 \%$ and $-7.2 \mathrm{mg} / \mathrm{dL}$, respectively). ${ }^{44}$

\section{Basal insulin dose and body weight}

At 6 months in EDITION 4, the basal insulin dose was approximately $18 \%$ higher with Gla-300 $(0.47 \mathrm{U} / \mathrm{kg} / \mathrm{d})$ than with Gla-100 (0.40 U/kg/d). Body weight increased in both groups, but at month 6 , the mean increase was smaller with Gla-300 (0.5 kg compared with $1.0 \mathrm{~kg} ; p=0.037) .{ }^{39}$ Similarly, in JP-1, basal insulin requirements were higher with Gla$300(0.35 \mathrm{U} / \mathrm{kg} / \mathrm{d})$ than with Gla-100 (0.29 U/kg/d), with little change in dose observed between months 6 and 12. ${ }^{40,44}$ However, there was a significant difference in body weight change at 6 months with Gla-300 ( $-0.1 \mathrm{~kg}$ compared with $+0.4 \mathrm{~kg} ; p=0.035$; Table 2). ${ }^{40}$ These contrasting results may be explained in part by the differences found in the BMI (ie, diet and lifestyle) and duration of diabetes between the populations, which could alter the effect of exogenous insulin requirements. ${ }^{40}$

\begin{tabular}{|c|c|c|c|c|c|}
\hline $\begin{array}{l}\text { Mean difference } \\
(95 \% \mathrm{CI})^{\mathrm{a}}\end{array}$ & $\begin{array}{l}\text { Body weight } \\
(\mathbf{k g})^{\mathrm{b}}\end{array}$ & $\begin{array}{l}\text { Mean difference } \\
(95 \% \mathrm{Cl})^{\mathrm{a}}\end{array}$ & $\begin{array}{l}\text { Basal insulin dose at end of } \\
\text { study (baseline) U/kg/d }\end{array}$ & $\begin{array}{l}\text { Difference at end of } \\
\text { study }(U / \mathrm{kg} / \mathrm{d})\end{array}$ & $\begin{array}{l}\text { \% Patients with } \\
\mathrm{HbA}_{\mathrm{Ic}}<7 \%\end{array}$ \\
\hline \multirow[t]{2}{*}{ NR } & +0.5 & $-0.6(-1.1 \text { to }-0.03)^{c}$ & $0.47(0.38)$ & +0.09 & 16.8 \\
\hline & +1.0 & & $0.40(0.37)$ & +0.03 & 15.0 \\
\hline \multirow[t]{2}{*}{$7.3(-10.4$ to 25.1$)$} & -0.1 & $-0.6(-1.1 \text { to }-0.0)^{c}$ & $0.35(0.28)$ & +0.07 & 15.6 \\
\hline & +0.4 & & $0.29(0.30)$ & -0.01 & 20.0 \\
\hline \multirow[t]{2}{*}{ NR } & NR & NR & $0.36(0.28)$ & +0.08 & NR \\
\hline & NR & & $0.28(0.30)$ & -0.02 & NR \\
\hline
\end{tabular}




\section{Type 2 diabetes (T2DM)}

Gla-300 was compared to Gla-100 in 4 RCTs, ${ }^{24,30,37,38}$ which enrolled a total of 2,737 participants with diverse background regimens. All participants were randomized to receive oncedaily injections of Gla-300 or Gla-100 administered in the evening (ie, from before the evening meal until bedtime). Three of these studies enrolled patients with high basal insulin doses ( $\geq 42 \mathrm{U} / \mathrm{d})$. The first study, EDITION 1, included participants not adequately controlled on basal and mealtime insulin (with or without metformin), ${ }^{30}$ while EDITION 2 and EDITION JP-2 included patients who had previously received basal insulin therapy in combination with OADs, but without injections of mealtime insulin. ${ }^{24,37}$ EDITION 3 included a population of insulin-naive subjects receiving background therapy with OADs. ${ }^{38}$ In the two studies of patients on previous basal insulin therapy plus OADs (EDITION 2, JP-2), the study designs were very similar, and prior OAD therapies were continued at stable doses. However, in EDITION 2, sulfonylureas were discontinued at randomization, ${ }^{37}$ whereas, in EDITION JP-2, sulfonylureas and glinides were continued throughout the study with doses adjusted for $\geq 2$ symptomatic or one severe hypoglycemic episode. ${ }^{24}$ The proportion of participants receiving sulfonylurea therapy, therefore, was much higher in the JP-2 study. ${ }^{24}$ In the insulinnaive population (EDITION 3), any sulfonylureas or glinides were discontinued at randomization, while metformin and dipeptidyl peptidase inhibitors were continued. ${ }^{38}$

The starting dose of basal insulin in the EDITION 3 was $0.2 \mathrm{U} / \mathrm{kg}$ in both treatment groups. ${ }^{38}$ For patients previously using once-daily basal insulin in EDITION 1, 2, and JP-2, the starting dose was the basal insulin dose used before randomization; in patients receiving twice-daily basal insulin, the starting dose was reduced by $20 \%{ }^{24,30}$

The two groups had similar characteristics at baseline (Table 1). Overall, the population at baseline had a mean age of 59 years, duration of diabetes of 13 years, $\mathrm{HbA}_{1 \mathrm{c}}$ of $8.2 \%$, body weight of $91.7 \mathrm{~kg}$, and BMI of $32.4 \mathrm{~kg} / \mathrm{m}^{2}$. Some differences between the trial populations included a shorter duration of diabetes in the insulin-naive population in EDITION $3^{38}$ (9.9 vs 14 years) and a lower body weight

Table 3 Efficacy of Gla-300 vs Gla-100 in patients with T2DM

\begin{tabular}{|c|c|c|c|c|c|c|c|c|}
\hline \multirow[t]{2}{*}{ Study } & \multirow{2}{*}{$\begin{array}{l}\text { Total } \\
\text { (n) }\end{array}$} & \multirow{2}{*}{$\begin{array}{l}\text { Duration } \\
\text { (months) }\end{array}$} & \multirow{2}{*}{$\begin{array}{l}\text { Background } \\
\text { regimen }\end{array}$} & \multirow[t]{2}{*}{ Comparators } & \multirow{2}{*}{$\begin{array}{l}n \text { in } \\
\text { each } \\
\text { group }^{a}\end{array}$} & \multicolumn{3}{|c|}{ Mean change from baseline to end of study } \\
\hline & & & & & & $\mathrm{HbA}_{\mathrm{lc}} \%$ & $\begin{array}{l}\text { Mean difference } \\
(95 \% \mathrm{Cl})^{\mathrm{b}}\end{array}$ & $\begin{array}{l}\text { FPG } \\
\mathbf{m g} / \mathbf{d L}\end{array}$ \\
\hline EDITION I & 807 & 6 & Basal insulin + & Gla-300 & 404 & -0.83 & $-0.00(-0.1$ I to $0.1 \mathrm{I})$ & -23 \\
\hline$(\text { Riddle et al) })^{30}$ & & & $\begin{array}{l}\text { mealtime } \\
\text { insulin }\end{array}$ & Gla-100 & 400 & -0.83 & & -25 \\
\hline EDITION I & $714^{d}$ & 12 & Basal insulin+ & Gla-300 & 359 & -0.86 & $-0.17(-0.30$ to -0.05$)$ & -30 \\
\hline $\begin{array}{l}\text { Extension } \\
\left(\text { Riddle et } \mathrm{al}^{41}\right)\end{array}$ & & & $\begin{array}{l}\text { mealtime } \\
\text { insulin }\end{array}$ & Gla-I00 & 355 & -0.69 & & -26 \\
\hline $\begin{array}{l}\text { EDITION } 2 \\
(\text { Yki Jarvinen } \\
\left.\text { et } \mathrm{al}^{37}\right)\end{array}$ & 811 & 6 & $\begin{array}{l}\text { Basal insulin + } \\
\text { OAD }\end{array}$ & $\begin{array}{l}\text { Gla-300 } \\
\text { Gla-100 }\end{array}$ & $\begin{array}{l}403 \\
405\end{array}$ & $\begin{array}{l}-0.57 \\
-0.56\end{array}$ & $-0.01(-0.14$ to 0.12$)$ & $\begin{array}{l}-21 \\
-19\end{array}$ \\
\hline $\begin{array}{l}\text { EDITION } 2 \\
\text { Extension } \\
(\text { Yki Jarvinen } \\
\text { et } \mathrm{al}^{42} \text { ) }\end{array}$ & $629^{d}$ & 12 & $\begin{array}{l}\text { Basal insulin + } \\
\text { OAD }\end{array}$ & $\begin{array}{l}\text { Gla-300 } \\
\text { Gla-100 }\end{array}$ & $\begin{array}{l}315 \\
314\end{array}$ & $\begin{array}{l}-0.55 \\
-0.50\end{array}$ & $-0.06(-0.22$ to 0.10$)$ & $\begin{array}{l}-15 \\
-18\end{array}$ \\
\hline $\begin{array}{l}\text { EDITION } 3 \\
\left(\text { Bolli et } \mathrm{al}^{38}\right)\end{array}$ & 878 & 6 & $\begin{array}{l}\text { Insulin } \\
\text { naïve + OAD }\end{array}$ & $\begin{array}{l}\text { Gla-300 } \\
\text { Gla-100 }\end{array}$ & $\begin{array}{l}432 \\
430\end{array}$ & $\begin{array}{l}-1.42 \\
-1.46\end{array}$ & $0.04(-0.09$ to 0.17$)$ & $\begin{array}{l}-61 \\
-68\end{array}$ \\
\hline $\begin{array}{l}\text { EDITION JP2 } \\
\left(\text { Terauchi et } \mathrm{al}^{24} \text { ) }\right.\end{array}$ & 241 & 6 & $\begin{array}{l}\text { Basal insulin + } \\
\text { OAD }\end{array}$ & $\begin{array}{l}\text { Gla-300 } \\
\text { Gla-100 }\end{array}$ & $\begin{array}{l}120 \\
120\end{array}$ & $\begin{array}{l}-0.45 \\
-0.55\end{array}$ & $0.10(-0.08$ to 0.27$)$ & $\begin{array}{l}-22 \\
-23\end{array}$ \\
\hline $\begin{array}{l}\text { EDITION JP2 } \\
\text { Extension } \\
\left(\text { Terauchi et al) }{ }^{43}\right.\end{array}$ & $222^{d}$ & 12 & $\begin{array}{l}\text { Basal insulin + } \\
\text { OAD }\end{array}$ & $\begin{array}{l}\text { Gla-300 } \\
\text { Gla-100 }\end{array}$ & $\begin{array}{l}107 \\
115\end{array}$ & $\begin{array}{l}-0.28 \\
-0.33\end{array}$ & NR & $\begin{array}{l}-13 \\
-18\end{array}$ \\
\hline Ritzel et $\mathrm{al}^{45}$ & 2,496 & 6 & $\begin{array}{l}\text { EDITION I, } \\
2,3 \text { trials }\end{array}$ & $\begin{array}{l}\text { Gla-300 } \\
\text { Gla-100 }\end{array}$ & $\begin{array}{l}1,239 \\
1,235\end{array}$ & $\begin{array}{l}-1.02 \\
-1.02\end{array}$ & $0.00(-0.08$ to 0.07$)$ & $\begin{array}{l}-37 \\
-41\end{array}$ \\
\hline $\begin{array}{l}\text { Ritzel et } \text { al }^{46} \\
\text { Extension }\end{array}$ & 2,496 & 12 & $\begin{array}{l}\text { EDITION I, } \\
2,3 \text { trials }\end{array}$ & $\begin{array}{l}\text { Gla-300 } \\
\text { Gla-I00 }\end{array}$ & $\begin{array}{l}1,011 \\
983\end{array}$ & $\begin{array}{l}-0.91 \\
-0.80\end{array}$ & $-0.10(-0.18$ to -0.02$)$ & $\begin{array}{l}\text { NR } \\
\text { NR }\end{array}$ \\
\hline
\end{tabular}

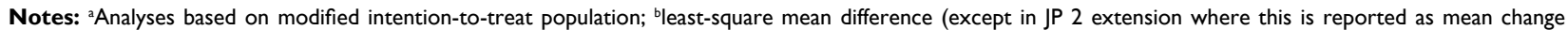
[standard deviation]); canalyses based on safety population; 'based on number of patients from the 6-month trial who completed I 2 months; ${ }^{\mathrm{e}} \mathrm{statistically} \mathrm{significant}$ vs Gla-100.

Abbreviations: T2DM, type 2 diabetes mellitus; $\mathrm{Cl}$, confidence interval; LS, least squares; Gla- 100 , insulin glargine $100 \mathrm{U} / \mathrm{mL}$; Gla-300, insulin glargine 300 U/mL; HbA glycosylated hemoglobin; FPG, fasting plasma glucose; OAD, oral antihyperglycemic drugs; NR, not reported. 
and BMI in Japanese patients in the EDITION JP-2 study ${ }^{24}$ compared to the more ethnically diverse and obese T2DM population enrolled in the other 3 studies $(66 \mathrm{~kg}$ vs $99.8 \mathrm{~kg}$ and $25.3 \mathrm{~kg} / \mathrm{m}^{2}$ vs $34.7 \mathrm{~kg} / \mathrm{m}^{2}$, respectively). ${ }^{30,37,38}$

Full published data of the 12-month extension trials in T2DM are available for 2 studies $^{41,42}$ and as an abstract in one small study in Japanese patients. ${ }^{43}$

\section{Glycemic control}

In EDITION 1 ( $\mathrm{n}=807)$, EDITION 2 ( $\mathrm{n}=811)$, EDITION $3(n=878)$, and EDITION JP-2 $(n=241)$, there was an equivalent reduction in $\mathrm{HbA}_{1 \mathrm{c}}$ from baseline to month 6 , demonstrating that in insulin-experienced (EDITION 1, 2, JP-2) and insulin-naive (EDITION 3 ) patients with T2DM, both Gla-300 and Gla-100 improved glycemic control. The results from these individual studies were also supported by a post hoc analysis from the 6-month pooled dataset of EDITION 1, EDITION 2, and EDITION $3(n=2,496) .{ }^{45}$ Additional data (available as abstracts) from the 6-month post hoc analyses of EDITION 1, 2, and 3 confirmed the comparable glycemic efficacy for Gla-300 vs Gla100 , irrespective of age ( $<65$ and $\geq 65$ years), BMI $(<30$ and $\geq 30 \mathrm{~kg} / \mathrm{m}^{2}$ ), diabetes duration ( $<10$ and $\geq 10$ years), concomitant administration of dipeptidyl peptidase-IV inhibitors, or renal function. ${ }^{48-51}$

In the individual extension studies, similar glycemic control was maintained over 12 months between the two treatment groups in patients receiving basal insulin plus OAD therapy, ${ }^{42,43}$ whereas there was a significant reduction in favor of Gla-300 in patients on basal plus mealtime insulin $(-0.17[95 \% \mathrm{CI}-0.30$ to -0.05$] \% ; p=0.007) .{ }^{41}$ These findings were supported by 1 -year post hoc patient-level pooled analyses of EDITION 1, 2, and 3, where there was a more sustained $\mathrm{HbA}_{1 \mathrm{c}}$ reduction in favor of Gla-300 at 1 year $(-0.10[95 \% \mathrm{CI}-0.18$ to -0.02$] \% ; p=0.0174$; available as an abstract). ${ }^{46}$

\section{Long-term glycemic effects}

In the 12-month extension studies of T2DM, glycemic control was comparable and sustained in two similar studies using

\begin{tabular}{|c|c|c|c|c|c|}
\hline & & & & & $\%$ Patients with \\
\hline $\begin{array}{l}\text { Mean difference } \\
(95 \% \mathrm{Cl})^{\mathrm{b}}\end{array}$ & $\begin{array}{l}\text { Body weight } \\
(\mathbf{k g})^{c}\end{array}$ & $\begin{array}{l}\text { Mean difference } \\
(95 \% \mathrm{Cl})^{\mathrm{b}}\end{array}$ & $\begin{array}{l}\text { Mean basal insulin dose at } \\
\text { end of study (baseline) } \mathrm{U} / \mathrm{kg} / \mathrm{d}\end{array}$ & $\begin{array}{l}\text { Mean change } \\
\text { from baseline }\end{array}$ & $\mathrm{HbA}_{\mathrm{Ic}}<7 \%$ \\
\hline \multirow[t]{2}{*}{ NR } & +0.9 & NR & $0.97(0.67)$ & +0.30 & 40 \\
\hline & +0.9 & & $0.88(0.67)$ & +0.21 & $4 I$ \\
\hline \multirow[t]{2}{*}{$-6.1(-12.5 \text { to } 0.2)^{\mathrm{e}}$} & +1.2 & $-0.2(-0.7$ to 0.3$)$ & $\mathrm{I} .03(0.67)$ & +0.36 & NR \\
\hline & $+\mathrm{I} .4$ & & $0.90(0.67)$ & +0.23 & NR \\
\hline \multirow[t]{2}{*}{$3.4(-2.7$ to 9.4$)$} & +0.08 & NR & $0.92(0.66)$ & +0.26 & 31 \\
\hline & +0.66 & & $0.84(0.68)$ & +0.16 & 30 \\
\hline \multirow[t]{2}{*}{$3.3(-3.7$ to 10.3$)$} & +0.4 & $-0.7(-1.3 \text { to }-0.2)^{\mathrm{e}}$ & $0.97(0.66)$ & +0.31 & NR \\
\hline & $+\mathrm{I} .2$ & & $0.87(0.68)$ & +0.19 & NR \\
\hline \multirow[t]{2}{*}{7.0 (I.8 to 12.2$)$} & +0.49 & NR & $0.62(0.0)$ & NR & 43 \\
\hline & +0.71 & & $0.53(0.0)$ & NR & 42 \\
\hline \multirow[t]{2}{*}{$0.8(-7.3$ to 8.8$)$} & -0.6 & $-1.0(-1.5 \text { to }-0.5)^{\mathrm{e}}$ & $0.35(0.25)$ & +0.10 & 30 \\
\hline & +0.4 & & $0.30(0.24)$ & +0.06 & 29 \\
\hline \multirow[t]{2}{*}{ NR } & -0.7 & NR & $0.36(0.25)$ & +0.11 & NR \\
\hline & +0.5 & & $0.30(0.24)$ & +0.06 & NR \\
\hline \multirow[t]{2}{*}{$3.8(0.54$ to 7.2$)$} & +0.51 & $-0.28(-0.55 \text { to }-0.01)^{\mathrm{e}}$ & $0.85(\mathrm{NR})$ & NR & 36 \\
\hline & +0.79 & & $0.76(N R)$ & NR & 36 \\
\hline \multirow[t]{2}{*}{ NR } & +0.85 & $-0.40(-0.7 \mathrm{I} \text { to }-0.09)^{\mathrm{e}}$ & 0.89 (NR) & NR & NR \\
\hline & +1.25 & & 0.78 (NR) & NR & NR \\
\hline
\end{tabular}


basal insulin plus OADs. ${ }^{42,43}$ There was a small but significant difference in reduction of $\mathrm{HbA}_{1 \mathrm{c}}$ favoring Gla-300 in EDITION 1 (basal plus mealtime insulin; -0.17 , 95\% CI: -0.30 to $-0.05 \% ; p=0.007) .{ }^{41}$ The more sustained $\mathrm{HbA}_{1 \mathrm{c}}$ reduction for Gla-300 at 1 year is also confirmed in the post hoc pooled data of EDITION 1, 2, and $3^{46}$ (Table 3 ).

Between months 6 and 12, basal insulin doses in all of the extension studies increased gradually in both treatment groups, to a greater extent in the Gla-300 group compared to the Gla-100 group; these differences were only statistically significant in EDITION $2(0.11 \mathrm{U} / \mathrm{kg} / \mathrm{d} ; p<0.0001)$. Similarly, the body weight difference observed at 6 months was maintained at 12 months $^{41}$ and was significantly lower with Gla-300 vs Gla-100 in patients on a regimen of basal insulin plus OADs $(-0.7 \mathrm{~kg}, 95 \% \mathrm{CI}:-1.3$ to $-0.2 ; p=0.009$; Table 3). ${ }^{42,43}$

\section{Secondary end points}

Similar reductions from baseline to 6 months were also seen in both Gla-300 and Gla-100 for secondary glycemic end points, including the proportion of patients achieving an $\mathrm{HbA}_{1 \mathrm{c}} \leq 7 \%$ or $\leq 6.5 \%$, the proportion of patients achieving a FPG $<120$ $\mathrm{mg} / \mathrm{dL}$ or $<100 \mathrm{mg} / \mathrm{dL}$, and in the change from baseline in laboratory-measured FPG. ${ }^{24,30,37,38}$ However, in insulin-naive patients, the mean change in laboratory-measured FPG was slightly greater in the Gla-100 group than in the Gla300 group: least-square mean difference of 7.0 (95\% CI: $1.8-12.2) \mathrm{mg} / \mathrm{dL} .{ }^{38}$ In addition to the more gradual decrease in prebreakfast SMPG with Gla-300, this small difference $(7.0 \mathrm{mg} / \mathrm{dL})$ may reflect differences in the pharmacokinetic and pharmacodynamic profiles of Gla-300 vs Gla-100, with Gla-300 delivering more even insulin action throughout the 24-hour period compared with Gla-100. ${ }^{38}$

Changes at 6 months in the mean 8-point SMPG profiles, preinjection SMPG, and variability in preinjection SMPG levels were similar in all of the EDITION studies, with relatively small between-treatment differences observed at month 6. ${ }^{24,30,37,38}$ However, in EDITION 2 (basal + OADs), the mean prebreakfast SMPG was lower with Gla-100 than with Gla-300 during the first 8 weeks (demonstrating that Gla-100 has a faster onset), with a more gradual decrease in prebreakfast SMPG in the Gla-300 group. At 6 months, a similar average prebreakfast SMPH was reached in both groups. ${ }^{37}$

\section{Basal insulin dose and body weight}

Increases in basal insulin doses occurred in both groups throughout the 6-month treatment period, with the majority of the increase occurring in the first 12 weeks (the first
8 weeks was the titration phase). Basal insulin doses were higher with Gla-300 than Gla-100 (+7-11 U/d), and overall, the Gla-300 group required $10 \%$ more basal insulin than the Gla-100 group. ${ }^{30,37,38}$ In contrast, the increase in basal insulin requirements was much lower (4 U/d) for the Japanese population in EDITION JP 2 (basal + OAD). ${ }^{24}$ This difference was attributed to the lower BMI found in the Japanese population with T2DM compared to the Western population (BMI of 25 and $35 \mathrm{~kg} / \mathrm{m}^{2}$, respectively). ${ }^{24,30,37,38}$ Despite the increase in basal insulin requirements, participants treated with Gla-300 either gained a similar amount of weight $(+0.9 \mathrm{~kg}$ in EDITION 1; basal + mealtime insulin) $)^{30}$ or weight gain was lower with Gla-300 compared to Gla-100..$^{24,37,38}$ Less weight gain in favor of Gla-300 was significant only in patients receiving basal insulin + OADs. ${ }^{24,37}$

\section{Safety and tolerability Hypoglycemia}

Hypoglycemia was analyzed using the incidence (or percentage) of participants experiencing $\geq 1$ event (relative risk) and the annualized event rates per participant-year (rate ratio) of exposure for intervals of time (full 6-month study period, baseline to week 8 , and week 9 to month 6) and categories of hypoglycemia. ${ }^{24,30,37,38}$ Hypoglycemic events were categorized using the American Diabetes Association (ADA) definitions and were analyzed according to the time of day that they occurred (daytime [0600-2359 hours], any time of day or night [24 hours], or nocturnal [0000-0559 hours]). Specific hypoglycemic categories included the following: 1) any hypoglycemia (confirmed by SMPG or not and whether symptomatic or asymptomatic; 2) documented symptomatic hypoglycemia ( $\leq 70 \mathrm{mg} / \mathrm{dL}$ ); 3 ) asymptomatic hypoglycemia (confirmed by SMPG $\leq 70 \mathrm{mg} / \mathrm{dL}$ ); and 4) severe hypoglycemia (events requiring assistance by another person). ${ }^{52}$ The predefined hypoglycemia category in all EDITION studies was confirmed ( $\leq 70 \mathrm{mg} / \mathrm{dL}$ ) or severe nocturnal hypoglycemia (0000-0559 hours) and hypoglycemia at any time (24 hours) for the interval periods between week 9 to month 6 and baseline to month 6 . These studies also analyzed all confirmed hypoglycemic events with an SMPG of $54 \mathrm{mg} / \mathrm{dL}$; however, these are not discussed in this review.

\section{Hypoglycemia in T2DM \\ Nocturnal hypoglycemia}

In EDITION 1, 2, and 3, the main prespecified secondary end point was the proportion of patients experiencing $\geq 1$ confirmed (SMPG of $\leq 70 \mathrm{mg} / \mathrm{dL}$ ) or severe nocturnal (0000-0559 hours) hypoglycemic events during the main- 
tenance period (week 9 to month 6). ${ }^{30,37,38}$ This was not a prespecified end point in EDITION JP 2. ${ }^{24}$

\section{Insulin-experienced}

In insulin-experienced patients with T2DM, despite differences in treatment regimens, the results of EDITION 1 (basal and mealtime insulin), EDITION 2, and JP 2 (basal insulin plus OADs) were consistent for nocturnal hypoglycemia. Across the 3 studies, Gla-300 demonstrated superiority over Gla-100 in reducing the risk of experiencing at least one confirmed ( $\leq 70 \mathrm{mg} / \mathrm{dL}$ ) or severe nocturnal hypoglycemic event. This reduction was consistently observed with Gla-300 during the entire study period from baseline to month 6 , as well as during the first 8 weeks (titration phase), and from week 9 to the end of 6 months (Table 4).

In EDITION 1, there was a $10 \%$ absolute and a $21 \%$ reduction in risk (RR: 0.79 [95\% CI: 0.67-0.93], $p=0.0045$ ); in EDITION 2, there was a $6 \%$ absolute and $23 \%$ relative decrease in risk (RR: 0.77 [95\% CI: 0.60-0.97], $p=0.038$ ); and in the Japanese population in EDITION JP 2, Gla300 was associated with a $19 \%$ absolute and $42 \%$ relative decrease in risk (RR: 0.58 [95\% CI: 0.40-0.85]) from week 9 to month 6 in all studies. ${ }^{24,30,37}$ Similarly, when looking at the annualized rates (events per participant-year) of confirmed ( $\leq 70 \mathrm{mg} / \mathrm{dL})$ or severe hypoglycemia across the 6-month study period, significant rate reductions were seen during the night $(29 \%, p=$ not reported; $48 \%, p=0.0010$; $55 \%, p=0.04$ in EDITION 1, 2, and JP 2, respectively). ${ }^{24,30,37}$

In the 12-month extensions, EDITION 1 and 2 $(n=1,994)$, Gla-300 exhibited a 16\% lower risk of nocturnal hypoglycemia that was maintained over a 1-year period (RR: 0.84, 95\% CI: 0.75-0.94 and RR: 0.84, 95\% CI: 0.71-0.99, respectively), ${ }^{41,42}$ whereas there was a $27 \%$ lower risk of nocturnal hypoglycemia maintained over the long term in a more culturally homogenous Japanese population enrolled in EDITION JP 2 (RR: 0.73, 95\% CI: 0.55-0.97). ${ }^{43}$

In a post hoc analysis of a patient population treated with basal insulin plus OADs (EDITION 2, n=808), all hypoglycemic event rates were generally lower with Gla-300 in subjects reaching SMPG $<130 \mathrm{mg} / \mathrm{dL}$ and those not reaching $\mathrm{SMPG}<100$ or $<130 \mathrm{mg} / \mathrm{dL}$ and event rates for any nocturnal hypoglycemia were significantly lower regardless of SMPG level achievement. ${ }^{53}$

\section{Insulin naive}

In general, superiority of Gla-300 over Gla-100 was not demonstrated with respect to the predefined main secondary end point in EDITION 3. The risk of nocturnal hypoglycemia from week 9 to month 6 did not significantly differ between insulin-naive patients with T2DM receiving treatment with Gla-300 and Gla-100. Nevertheless, with Gla-300 relative to Gla-100, the risk of experiencing at least one nocturnal event that was severe or confirmed $(\leq 70 \mathrm{mg} / \mathrm{dL})$ was $24 \%$ lower over the entire 6-month treatment period (RR: 0.76 [95\% CI: 0.59-0.99]). The annualized event rates of nocturnal confirmed or severe hypoglycemia were also similar for Gla-300 vs Gla-100. ${ }^{38}$ An extension study to 12 months has been completed, but not yet published.

\section{Hypoglycemia at any time of day ( 24 hours)}

In insulin-experienced patients with T2DM, the percentage of patients experiencing $\geq 1$ confirmed or severe hypoglycemic event at any time ( 24 hours) over 6 months was comparable in patients receiving basal plus mealtime insulin ${ }^{30}$ or reduced by $10 \%-14 \%$ in patients receiving basal insulin plus OADs with Gla-300 compared with Gla-100, RR: 0.90 (95\% CI: $0.83-$ $0.98)$ and RR: 0.86 (95\% CI: 0.83-1.01), respectively. ${ }^{24,37}$

In insulin-naive patients, the relative reduction of confirmed or severe hypoglycemia with Gla-300 over months was 12\% (RR: 0.88 [95\% CI: 77-1.01]), whereas the annualized event rate was significantly lower with Gla-300 (6.4 vs 8.5 events per participant-year; RR: 0.75 [95\% CI: 0.57-0.99]; $p=0.042) .{ }^{38}$ Notably, in EDITION 3, these benefits in terms of lower hypoglycemia risk were observed in the absence of sulfonylureas, which in previous studies of starting basal insulin were associated with greater rates of hypoglycemia events per participant-year. ${ }^{38}$

\section{Long-term 12-month extension studies}

In T2DM demonstrated that confirmed or severe hypoglycemic events at any time of day ( 24 hours) were numerically lower but not significantly different with Gla-300 compared to Gla-100 (Table 4). ${ }^{41-43}$

\section{Switching from twice-daily basal insulin to once-daily Gla-300}

In a post hoc subgroup analysis, people with T2DM enrolled in EDITION 1 (basal + mealtime insulin) and EDITION 2 (basal + OADs) who were switched from twice-daily basal insulin to once-daily Gla-300 or Gla-100 received comparable glycemic control with less hypoglycemia with Gla-300 vs those switching to Gla-100 over a 6-month period. ${ }^{54}$

\section{Hypoglycemia in TIDM}

Over 6 months, in both EDITION $1(n=549)$ and JP $1(n=243)$, the incidence (relative risk) of confirmed 
Table 4 Percent of $\geq$ I confirmed hypoglycemic $(\leq 70 \mathrm{mg} / \mathrm{dL})$ or severe hypoglycemia events in TIDM and T2DM patients

\begin{tabular}{|c|c|c|c|c|c|c|c|}
\hline \multirow[t]{3}{*}{ Trial } & \multirow[t]{3}{*}{$\mathbf{N}^{\mathbf{a}}$} & \multirow{3}{*}{$\begin{array}{l}\text { Background } \\
\text { regimen }\end{array}$} & \multirow{3}{*}{$\begin{array}{l}\text { Pre-specified time } \\
\text { periods }\end{array}$} & \multirow[t]{3}{*}{ Comparators } & \multicolumn{3}{|c|}{ Nocturnal hypoglycemia (24 h) } \\
\hline & & & & & \multicolumn{3}{|c|}{$\%$ Participants } \\
\hline & & & & & $\leq 70 \mathrm{mg} / \mathrm{dL}^{\mathrm{b}}$ & $\begin{array}{l}\text { Relative risk vs } \\
\text { Gla-100 (95\% Cl) }\end{array}$ & p-Value \\
\hline \multicolumn{8}{|l|}{ TIDM } \\
\hline EDITION $4^{39}$ & 549 & Basal + mealtime insulin & Baseline to month 6 & Gla-300 & 69 & $0.98(0.88-1.09)$ & NS \\
\hline \multirow[t]{3}{*}{6 month } & & & & Gla- 100 & 70 & & \\
\hline & & & Week 9 to month 6 & Gla-300 & 59 & $1.06(0.92-1.23)$ & NS \\
\hline & & & & Gla- 100 & 56 & & \\
\hline EDITION JP I 40 & 243 & Basal + mealtime insulin & Baseline to month 6 & Gla-300 & 69 & $0.85(0.73-0.99)$ & NR \\
\hline \multirow[t]{3}{*}{6 month } & & & & Gla- 100 & 81 & & \\
\hline & & & Week 9 to month 6 & Gla-300 & 62 & $0.84(0.70-1.00)$ & NS \\
\hline & & & & Gla- 100 & 74 & & \\
\hline EDITION JP I ${ }^{44}$ & 228 & Basal + mealtime insulin & Baseline to month 12 & Gla-300 & NR & NR & NR \\
\hline 12 month & & & & Gla- 100 & NR & & \\
\hline \multicolumn{8}{|l|}{ T2DM } \\
\hline EDITION I 30 & 807 & Basal + mealtime insulin & Baseline to month 6 & Gla-300 & 45 & $0.78(0.68-0.89)$ & NR \\
\hline \multirow[t]{3}{*}{6 month } & & & & Gla- 100 & 58 & & \\
\hline & & & Week 9 to month 6 & Gla-300 & 36 & $0.79(0.67-0.93)$ & $p=0.004$ \\
\hline & & & & Gla-100 & 46 & & \\
\hline EDITION I ${ }^{4 I}$ & 806 & Basal + mealtime insulin & Baseline to month 12 & Gla-300 & 55 & $0.84(0.75-0.94)$ & NR \\
\hline 12 month & & & & Gla- 100 & 65 & & \\
\hline EDITION $2^{37}$ & 811 & Basal + OAD & Baseline to month 6 & Gla-300 & 28 & 0.7 I (0.58-0.86) & NR \\
\hline \multirow[t]{3}{*}{6 month } & & & & Gla- 100 & 40 & & \\
\hline & & & Week 9 to month 6 & Gla-300 & 22 & $0.77(0.60-0.97)$ & $p=0.038$ \\
\hline & & & & Gla- 100 & 28 & & \\
\hline EDITION $2^{42}$ & 811 & Basal + OAD & Baseline to month 12 & Gla-300 & 38 & $0.84(0.7 \mathrm{I}-0.99)$ & NR \\
\hline 12 month & & & & Gla- 100 & 45 & & \\
\hline EDITION $3^{38}$ & 878 & Insulin naïve & Baseline to month 6 & Gla-300 & 18 & $0.76(0.59-0.99)$ & NR \\
\hline \multirow[t]{3}{*}{6 month } & & & & Gla- 100 & 24 & & \\
\hline & & & Week 9 to month 6 & Gla-300 & 15 & $0.90(0.67-1.22)$ & NR \\
\hline & & & & Gla-100 & 17 & & \\
\hline EDITION JP2 ${ }^{24}$ & 241 & Basal + OAD & Baseline to month 6 & Gla-300 & 28 & $0.62(0.44-0.88)$ & NR \\
\hline \multirow[t]{3}{*}{6 month } & & & & Gla-100 & 46 & & \\
\hline & & & Week 9 to month 6 & Gla-300 & 25 & $0.58(0.40-0.85)$ & NR \\
\hline & & & & Gla- 100 & 44 & & \\
\hline EDITION JP2 ${ }^{43}$ & 222 & Basal + OAD & Baseline to month 12 & Gla-300 & 38 & $0.73(0.55-0.97)$ & NR \\
\hline 12 month & & & & Gla- 100 & 53 & & \\
\hline Ritzel et $\mathrm{a}^{45}$ & 2,496 & EDITION I, 2, 3 & Baseline to month 6 & Gla-300 & NR & $0.75(0.68-0.83)$ & NR \\
\hline \multirow[t]{3}{*}{6 month } & & & & Gla- 100 & NR & & \\
\hline & & & Week 9 to month 6 & Gla-300 & NR & NR & NR \\
\hline & & & & Gla- 100 & NR & & \\
\hline Ritzel et $\mathrm{a}^{46}$ & 2,496 & EDITION I, 2, 3 trials & Baseline to month 12 & Gla-300 & NR & $0.85(0.77-0.92)$ & NR \\
\hline 12 month & & & & Gla- 100 & NR & & \\
\hline
\end{tabular}

Notes: aSafety population Gla-100; bdata have been rounded; Bold text represents statistically significant vs Gla- 100.

Abbreviations: TIDM, type I diabetes mellitus; T2DM, type 2 diabetes mellitus; Gla-100, insulin glargine $100 \mathrm{U} / \mathrm{mL}$; Gla-300, insulin glargine 300 U/mL; NR, not reported; NS, not significant; $\mathrm{Cl}$, confidence interval; OAD, oral antidiabetic drugs; RR, relative risk (\% participants) and rates ratio (events/patient-year); h, hours.

( $<70 \mathrm{mg} / \mathrm{dL}$ ) or severe nocturnal (0000-0559 hours) hypoglycemia at any time of day ( 24 hours) between week 9 and month 6 did not significantly differ between Gla-300 and Gla-100. ${ }^{39,40}$ The incidence of hypoglycemia with Gla-300 did not differ even when analyzed by morning or evening injection time. ${ }^{39}$ However, when the annualized rates were reported in the homogenous Japanese population, the event rates of confirmed $(\leq 70 \mathrm{mg} / \mathrm{dL})$ or severe hypoglycemia with Gla-300 were $20 \%$ and $34 \%$ lower than that for Gla100 for events occurring at any time (24 hours) and at night (0000-0559 hours), respectively. ${ }^{40}$ This was particularly apparent during the first 8 weeks of the insulin titration phase. ${ }^{40}$ This is consistent with results from a multinational population in EDITION 4, in which there was a 31\% lower rate of nocturnal confirmed or severe hypoglycemia observed in the first 8 weeks with Gla-300 vs Gla-100 (although 


\begin{tabular}{|c|c|c|c|c|c|c|c|}
\hline \multirow{2}{*}{\multicolumn{3}{|c|}{ Annualized rate }} & \multicolumn{5}{|c|}{ Hypoglycemic at any time of day (24 h) } \\
\hline & & & \multicolumn{2}{|c|}{ \% Participants } & \multicolumn{3}{|c|}{ Annualized rate } \\
\hline $\begin{array}{l}\text { Events/ } \\
\text { patient-year }\end{array}$ & Rate ratio $(95 \% \mathrm{Cl})$ & $p$-Value & $\leq 70 \mathrm{mg} / \mathrm{dL}$ & $\begin{array}{l}\text { Relative risk vs Gla- } 100 \\
(95 \% \mathrm{Cl})\end{array}$ & $\begin{array}{l}\text { Events/ } \\
\text { patient year }\end{array}$ & $\begin{array}{l}\text { Rate ratio } \\
(95 \% \mathrm{Cl})\end{array}$ & p-Value \\
\hline 8.0 & $0.90(0.7 I-1.14)$ & NS & 93 & $1.00(0.95-1.04)$ & 78 & $1.09(0.94-1.25)$ & NS \\
\hline \multirow[t]{3}{*}{9.0} & & & 94 & & 73 & & \\
\hline & $1.04(0.80-1.36)$ & NS & 82 & $0.98(0.91-1.06)$ & & $1.16(0.98-1.37)$ & NS \\
\hline & & & 84 & & & & \\
\hline 7.5 & $0.66(0.48-0.92)$ & NR & 97 & $0.99(0.95-1.04)$ & 75.3 & $0.80(0.65-0.98)$ & NR \\
\hline 11.2 & & & 98 & & 94.8 & & \\
\hline 7.5 & $0.7 \mathrm{I}(0.49-1.01)$ & NR & 94 & I.0I (0.95-I.08) & 71.9 & $0.86(0.69-1.07)$ & NR \\
\hline 10.5 & & & 93 & & 83.6 & & \\
\hline NR & NR & NR & NR & NR & NR & NR & NR \\
\hline NR & & & NR & & NR & & \\
\hline 3.1 & $0.75(0.58-0.95)$ & NR & 82 & $0.93(0.88-0.99)$ & 25.5 & $0.95(0.80-1.13)$ & NR \\
\hline 4.2 & & & 88 & & 26.8 & & $N R$ \\
\hline 3.0 & $0.73(0.55-0.98)$ & NR & 75 & $0.96(0.89-1.04)$ & 24.4 & $0.99(0.82-1.19)$ & $N R$ \\
\hline 4.0 & & & 78 & & 24.7 & & NR \\
\hline 2.9 & $0.90(0.70-1.16)$ & NR & 86 & $0.94(0.89-0.99)$ & 22.3 & $1.06(0.89-1.27)$ & $N R$ \\
\hline 3.2 & & & 92 & & 21.0 & & NR \\
\hline 1.9 & $0.52(0.35-0.77)$ & $p=0.001$ & 70 & $0.90(0.83-0.98)$ & 14.0 & NR & NR \\
\hline 3.7 & & & 77 & & 18.1 & & $N R$ \\
\hline 1.9 & NR & NR & 59 & 0.91 (0.82-1.02) & 13.6 & NR & $N R$ \\
\hline 3.2 & & & 65 & & 16.2 & & NR \\
\hline 1.7 & $0.63(0.42-0.96)$ & NR & 78 & $0.96(0.89-1.02)$ & 11.6 & $0.88(0.7 \mathrm{I}-1.09)$ & $N R$ \\
\hline 2.8 & & & 82 & & 13.2 & & NR \\
\hline 1.3 & $0.98(0.64-1.48)$ & NR & 46 & $0.88(0.77-1.01)$ & 6.4 & $0.75(0.57-0.99)$ & NR \\
\hline 1.3 & & & 53 & & 8.5 & & $N R$ \\
\hline 1.6 & $1.08(0.66-1.77)$ & NR & 40 & $0.86(0.74-1.00)$ & 7.3 & $0.81(0.60-1.10)$ & NR \\
\hline 1.4 & & & 46 & & 9.0 & & NR \\
\hline 2.2 & $0.45(0.21-0.96)$ & $p=0.040$ & 65 & $0.86(0.73-1.01)$ & 10.5 & $0.64(0.43-0.96)$ & $N R$ \\
\hline 5.0 & & & 77 & & 16.5 & & NR \\
\hline 2.2 & $0.37(0.16-0.83)$ & NR & 60 & $0.84(0.70-1.01)$ & 11.2 & $0.67(0.43-1.04)$ & NR \\
\hline 6.0 & & & 72 & & 16.9 & & NR \\
\hline 2.1 & $0.4 \mathrm{I}(0.18-0.92)$ & NR & NR & $N R$ & NR & NR & NR \\
\hline 5.3 & & & NR & & NR & & NR \\
\hline 2.1 & $0.69(0.57-0.84)$ & $p=0.0002$ & NR & $0.91(0.87-0.96)$ & 15.2 & $0.86(0.77-0.97)$ & $p=0.0116$ \\
\hline 3.1 & & & NR & & 17.7 & & \\
\hline NR & NR & NR & NR & NR & $N R$ & NR & NR \\
\hline NR & & & NR & & $N R$ & & \\
\hline NR & $0.82(0.67-0.99)$ & NR & NR & $0.94(0.90-0.98)$ & NR & 0.97 (0.87-1.09) & $N R$ \\
\hline NR & & & NR & & NR & & \\
\hline
\end{tabular}

this was not maintained over the whole study period). In JP 1, the significantly lower rate of hypoglycemia at any time of day (24 hours) and at night (0000-0559 hours) from baseline to month 6 was not reflected in EDITION 4 , where no between-treatment differences in rates at any time of day and night were observed. ${ }^{39,40}$ In the 12-month Japanese extension, the rates (events per participant-year) and percentage of participants experiencing $\geq 1$ nocturnal confirmed $(<70 \mathrm{mg} / \mathrm{dL})$ or severe hypoglycemic event were comparable between groups ${ }^{44}$ (Table 4 ).

\section{Hypoglycemia data from post hoc pooled analysis}

All the available pooled analyses were conducted in T2DM. The pooled analysis of EDITION 1, 2, and $3(n=2,474)$ showed there was a lower relative risk for confirmed or 
severe hypoglycemia at any time ( 24 hours) and at night (00:00-05:59 hours) in favor of Gla-300 at 6 months $^{45}$ and at 12 months (available as an abstract). ${ }^{46}$

Over the 6-month treatment period, the frequency of patients who had at least one confirmed hypoglycemic event at any time (24 hours) was approximately $6 \%(n=78)$ fewer patients reporting at least one event in the Gla-300 group and $10 \%(n=121)$ fewer patients in the Gla-300 group who reported at least one nocturnal hypoglycemic event. The annualized rate of confirmed or severe nocturnal events was $31 \%$ lower with Gla-300 compared with Gla-100 (2.10 events per participant-year with Gla-300 and 3.06 with Gla-100; RR: 0.69 , 95\% CI: $0.57-0.84, p=-0.0002$; mainly driven by the findings of EDITION 1 and 2). This is a reduction of approximately one confirmed or severe nocturnal event per person per year, which is of debatable clinical significance. A further subgroup analysis of the pooled data demonstrated that the lower risk of confirmed or severe hypoglycemia in favor of Gla-300 was not affected by age ( $<65$ or $\geq 65$ years), BMI ( $<30$ or $\geq 30 \mathrm{~kg} / \mathrm{m}^{2}$ ), duration of diabetes, or presence of mild-to-moderate renal impairment. ${ }^{48,51}$

It should be noted that the beneficial effects of Gla300 on nocturnal hypoglycemia were also apparent when the prespecified nocturnal period (0000-0559 hours) was changed to a clinically defined window of 2200 hours to prebreakfast SMPG ${ }^{55}$ and extended to a potentially more vulnerable subgroup aged $\geq 65$ years. ${ }^{49}$ In a more recent analysis (of EDITION 1, 2, and 3) that included a much broader predefined window than previous (2200-0559 hours, 0000-0759 hours, 2200 hours to prebreakfast SMPG), the beneficial effect of Gla-300 on nocturnal hypoglycemia continued to be apparent; however, the total number of events was consistently greatest for period 2200 hours to prebreakfast SMPG vs other windows. The corresponding annualized rates were lower in favor of Gla-300 for all windows (34\% for 2200-0559 hours; 30\% for 0000-0759 hours; 29\% for 2200 hours to prebreakfast SMPG).${ }^{56}$ Furthermore, people treated with Gla-300 experienced a consistently lower rate of confirmed or severe hypoglycemia vs those treated with Gla-100, regardless of $\mathrm{HbA}_{1 \mathrm{c}}$ over 6 months of treatment. ${ }^{57}$

In a trilevel meta-analysis in T2DM (using pooled data from the BEGIN and EDITION programs), comparing Gla-300 and insulin degludec (IDeg) to Gla-100, the risk of confirmed $(\leq 70 \mathrm{mg} / \mathrm{dL})$ or severe hypoglycemia was lower with IDeg vs Gla-100 at night (0001-0559 hours) but comparable at any time ( 24 hours). Gla-300 provided a lower risk of anytime and nocturnal hypoglycemia (available as an abstract). ${ }^{58}$ In a network (NMA) comparison that indirectly compared Gla-300 vs other available basal insulins, Gla-300 was associated with a significantly lower risk of nocturnal hypoglycemia (64\%-82\% lower) when compared with NPH $(0.18 ; 0.05-0.55)$ and premixed insulin $(0.36 ; 0.14-0.94)$. The hypoglycemia risks were comparable to insulin detemir and degludec. ${ }^{47}$

\section{Adverse events}

Other safety end points included occurrence of treatmentemergent adverse events (TEAEs) and injection site reactions. Information from the individual 6-month EDITION and extension trials indicate a comparable and infrequent rate of TEAEs and treatment-emergent severe AEs. ${ }^{24,30,37-42}$ The patient-level meta-analysis of the EDITION 1, 2, and 3 showed that TEAEs were reported by $57 \%$ participants in the Gla-300 group and 54\% participants in the Gla-100 group. The most common TEAEs were infections and infestations (most commonly nasopharyngitis and upper respiratory tract infection), nervous system disorders, gastrointestinal disorders, and musculoskeletal and connective tissue disorders. ${ }^{45}$

In type 1 or 2 patients on basal plus mealtime insulin, injection site reactions were slightly higher for Gla-300 $(2.2 \%)$ compared to Gla-100 (1.5\%). ${ }^{30,39}$ In patients on basal insulin plus OADs for 12 months, injection site reactions were either higher or lower for Gla-300 vs Gla-100 (3.0\% vs 1.5\% and $1.2 \%$ vs $3.0 \%$, respectively), ${ }^{41,42}$ whereas insulin-naive patients experienced a higher level of injection site reactions compared to the insulin-experienced population, but there was no difference found between the two groups ( $4 \%$ vs $5 \%$, respectively). ${ }^{38}$

\section{Patient-reported outcomes}

Treatment satisfaction and perception of occurrence of hypo- and hyperglycemia were assessed using the validated Diabetes Treatment Satisfaction Questionnaire. Treatment satisfaction scores and the perceived frequency of hypoglycemia were similar between treatment groups, and satisfaction generally improved from baseline to month 6, ${ }^{30,37-39}$ and was maintained at month 12 , resulting in an overall mean increase from baseline to month 12 of 4.3 with Gla-300 and 4.4 with Gla-100. Perceived frequency of hypoglycemia remained stable with both treatment and perceived frequency of hyperglycemia slightly decreased in both treatment groups from baseline to month $12 .{ }^{42}$

\section{Use in special populations}

There are no clinical studies of Gla-300 in pregnant women, in children and adolescents below 18 years of age, and 
in patients with hepatic impairment. Therefore, Gla-300 has not yet been demonstrated to be safe and effective in these populations. Subgroup analysis in an elderly population ( $\geq 65$ years of age) and in people with mild-tomoderate renal impairment suggests that Gla-300 can be used in this population with frequent monitoring and dose adjustment. ${ }^{48,49,51,59}$

\section{Flexibility in dosing time}

The PK and PD profile of Gla-300 extending beyond 24 hours suggested a greater flexibility in basal insulin injection time; therefore, the efficacy and safety of flexible dosing (24 \pm up to 3 hours) was compared to fixed dosing ( 24 hours) intervals in two 12-week substudies following the main 6-month treatment period within EDITION 1 and EDITION $2(\mathrm{n}=194){ }^{60}$ The primary efficacy end point was the change in $\mathrm{HbA}_{1 \mathrm{c}}$ from baseline to the end of the 3-month substudy. Secondary end points included the change in FPG and daily basal insulin doses, and confirmed nocturnal (0000-0559 hours) and any time (24 hours) hypoglycemia. Administration with a flexible dosing time (within 3 hours before or after the usual time of administration) had no effect on glycemic control and the incidence of hypoglycemia. ${ }^{60}$

\section{Dosing and administration}

Gla-300 is available in a multidose, SoloStar (Sanofi-Aventis) disposable prefilled pen packaged in boxes of three or five pens (each pen contains $1.5 \mathrm{~mL}$ of solution equivalent to $450 \mathrm{U}$ of Gla-300). Each pen device allows the administration of Gla-300 doses up to a maximum of 80 units (in 1 unit increments) in a single injection. The higher concentration of Gla-300 was specifically designed to deliver the same number of insulin units in one-third of the volume as Gla-100; therefore, it does not require any further dose conversion. ${ }^{61} \mathrm{It}$ is recommended to be administered via subcutaneous injection once daily, at the same time each day ${ }^{25}$ or at any time (preferably at the same time) of the day. ${ }^{26}$ Patients have the flexibility to administer Gla-300 up to 3 hours before or after their usual time of administration without losing glycemic control. ${ }^{60}$ Gla-300 has the same administration, storage, and expiration instructions as Gla-100. ${ }^{25}$ The recommended starting dose of Gla-300 in insulin-naive patients with T2DM is $0.2 \mathrm{U} / \mathrm{kg} / \mathrm{d}$. The starting dose in insulin-naive patients with T1DM is $0.2-0.4 \mathrm{U} / \mathrm{kg} / \mathrm{d}$ with approximately $33 \%-50 \%$ of the total daily dose requirement given as Gla-300 insulin and the remainder provided as mealtime insulin divided between each meal. ${ }^{25}$

\section{Switching insulins in insulin-experienced patients}

Gla-300 and Gla-100 are not bioequivalent and cannot be used interchangeably. In patients switching from a once-daily basal insulin, the starting dose of Gla-300 can be done on a unit-to-unit basis, and should be the same as the once-daily basal insulin dose, but a higher Gla-300 dose (approximately $10 \%-18 \%$ ) may be needed to achieve target ranges for plasma glucose levels. When switching from twice-daily basal insulins, the recommended starting dose of Gla- 300 is $80 \%$ of the total daily dose of basal insulin that is being discontinued. ${ }^{25,26}$ When switching from Gla-300 to Gla-100, the dose should be reduced by approximately $20 \%$ to reduce the risk of hypoglycemia. ${ }^{26}$ Steady-state insulin levels are reached in 5 days, and dose titration is recommended no more frequently than every 3-4 days to minimize the risk of hypoglycemia. ${ }^{25}$

\section{Comparison of Gla-300 insulin pen to other commercial insulin pens}

In a laboratory-based injection-force study, Gla-300 SoloStar demonstrated comparable dose accuracy and greater reproducibility compared with the Flexpen (Novo Nordisk A/S, Bagsvaerd, Denmark) and Kwikpen (Eli Lilly \& CO, Indianapolis, IN, USA), but with a lower injection force. ${ }^{61} \mathrm{~A}$ 4-week study of insulin- and pen-naive patients with T2DM $(n=40)$ found the Gla-300 SoloStar disposable pen reliable, easy to learn, and easy to use. ${ }^{62} \mathrm{In}$ an interview-based survey, Gla-300 SoloStar pen was ranked first by more patients with T1DM $(n=26)$ or T2DM $(n=228)$ as being the easiest to use and inject than three other disposable insulin pens (Gla-100 SoloStar, insulin aspart Flexpen, and insulin lispro Kwikpen) ${ }^{63}$

\section{Real-world application}

The clinical outcomes of early users of Gla-300 in the realworld primary care setting were assessed in a retrospective study using data extracted from 24 US-based integrated delivery network systems. ${ }^{64}$ Eight hundred and eighty one patients with T2DM who used other basal insulins within the 6 months prior to Gla-300 initiation (defined as having $>1$ prescription order of Gla-300 over a 10-month period) and up to 6 months after Gla-300 initiation were identified. $\mathrm{HbA}_{1 \mathrm{c}}$ assessments at baseline and during following up were extracted for a small subset $(n=267)$ of patients and hypoglycemic events ( $n=449)$ were identified based on ICD9-CM diagnosis codes or blood glucose $\leq 70 \mathrm{mg} / \mathrm{dL}$. Patient 
demographics included a mean age of 60 years, $\mathrm{HbA}_{1 \mathrm{c}}$ of $9 \%$ with a high prevalence of the following comorbidities: hypertension, dyslipidemia, and diabetes-related complications. Switching to Gla-300 was associated with improved glycemic control (mean estimated reduction of $0.64 \%, p<0.0001$ ) and decreased occurrence of hypoglycemia ( $6 \%$ vs $5 \%$, baseline vs follow-up) ${ }^{64}$

In another study (available as an abstract), real-world performance measures based on national benchmark standards (ie, ADA, and US National Committee for Quality Assurance-Healthcare Effectiveness Data and Information Set 2014) were applied to the dataset of EDITION 3 (insulinnaive patients) to assess glycemic control and incidence of hypoglycemia. ${ }^{65}$ Patients were stratified into low risk (LR; without comorbidities and age $<65, n=629$ ) or high risk (HR; age $\geq 65$ years and/or having $\geq 1$ selected comorbidity, $\mathrm{n}=233$ ) groups. In the LR cohort, comparable percentages of Gla-300 and Gla-100 patients achieved $\mathrm{A}_{1 \mathrm{c}}<7 \%(p=0.9)$, and a significantly higher proportion of Gla-300 treated patients achieved $\mathrm{A}_{1 \mathrm{c}}<7 \%$ without severe or confirmed 24 hours hypoglycemia compared with Gla-100 (22\% vs $15 \%$, respectively; $p=0.025$ ). In the HR cohort, comparable percentages of Gla-300- and Gla-100-treated patients achieved an $A_{1 c}$ level $<8 \%(p=0.275)$. Similarly, a higher proportion of Gla-300-treated patients achieved $A_{1 c}<8 \%$ without severe or confirmed hypoglycemia compared with Gla-100-treated patients ( $37 \%$ vs $28 \%$, respectively; $p=0.174$ ). Thus, using real-world diabetes performance measures, patients in the LR cohort treated with Gla-300 were more likely to achieve target $\mathrm{A}_{1 \mathrm{c}}$ levels without severe or confirmed hypoglycemia compared with Gla-100-treated patients. ${ }^{65}$

\section{Conclusion}

Clinically, insulin-resistant patients present a very difficult therapeutic challenge. Obese diabetic patients often require huge insulin doses, and with rising doses of available basal U-100 insulin products, there is a "law of diminishing returns." In other words, high insulin doses provide little additional efficacy (glucose lowering) but often generate undesirable side effects (hypoglycemia, weight gain, and fluid retention). Part of this problem is thought to be due to insulin bioavailability. Once insulin volume exceeds $0.5 \mathrm{~mL}$, pharmacokinetic curves begin to fall apart because of the large subcutaneous insulin depot that takes longer to absorb; this delays clinical insulin action. It is here that concentrated insulins, such as Eli Lilly's U-500 concentrated insulin, have shown clinical benefit. Equivalent doses of more concentrated insulins often yield superior clinical results. ${ }^{66,67}$
U-300 glargine insulin offers the potential for similar efficacy and lower insulin doses, potentially leading to fewer side effects at high doses. The extended duration of action and more consistent within-day profile of Gla-300 make this insulin analog attractive as a true once-daily basal insulin replacement. The Phase III EDITION trials were adequately powered to demonstrate a noninferiority margin of $0.4 \%$ for the comparison to Gla-100. In summary, all of the 6-month EDITION trials showed that Gla-300 provided noninferior $\mathrm{HbA}_{1 \mathrm{c}}$ lowering compared with Gla-100, with glycemic control maintained over 12 months. ${ }^{24,30,37-40,42-44}$ There was only a small but significant difference in $\mathrm{HbA}_{1 \mathrm{c}}$ reduction at 12 months favoring Gla-300 in insulin-experienced patients with T2DM using basal plus mealtime insulin $(p=0.007) .41,46$

Basal insulin doses for Gla-300 needed to achieve equivalent glycemic control were higher than for Gla-100, both in patients with T2DM (10\% higher) and T1DM (18\% higher). ${ }^{30,37-39}$ This increase was not observed in Japanese patients with T2DM. ${ }^{24}$ Despite the higher dose, $\operatorname{similar}^{30}$ or smaller weight changes ${ }^{24,37-40}$ were seen in participants receiving Gla-300 vs Gla-100. Weight loss was only statistically significant in T2DM patients on a combination of basal insulin plus $\mathrm{OAD}^{37}$ and in Japanese patients..$^{24,40}$ This difference observed in the Japanese population may be attributed to a lower BMI and a shorter duration of diabetes, compared to the heavier and more ethnically diverse multinational population included in the EDITION studies.

Despite equivalent efficacy in terms of glycemic control, the use of Gla-300 in patients with T1DM resulted in no difference in the incidence of nocturnal or hypoglycemia at any time of day (24 hours). Annualized event rates were $20 \%-34 \%$ lower only in the first 8 weeks of the titration phase. ${ }^{39,40}$

In contrast, the findings of hypoglycemia in patients with T2DM were different depending on prior exposure to insulin. In insulin-naive patients, there was a $12 \%$ reduction in daytime hypoglycemia from week 9 to month 6 , but no difference between groups in nocturnal hypoglycemia. ${ }^{38}$ On the other hand, in insulin-experienced patients, Gla-300 demonstrated superiority over Gla-100 in reducing the risk of nocturnal hypoglycemia by $21 \%-23 \%, 30,37$ or by $42 \%$ in Japanese patients. ${ }^{24}$ However, there was no difference ${ }^{30}$ or just a small $10 \%-14 \%$ risk reduction ${ }^{24,37}$ in hypoglycemia at any time of day (24 hours).

It stands to reason that more consistent basal insulins such as Glargine U-300 would best lower the incidence of hypoglycemia during overnight hours. During the day, variables such as diet, physical activity, and stressors often affect insulin 
requirements, while rapid-acting insulins predominate for generating hypoglycemic events. At night, basal insulin activity predominates. As a result, more stable long-acting insulins would be expected to minimize nocturnal hypoglycemia. In addition, since patients are sleeping overnight, usual warning signs such as hunger cannot protect them from hypoglycemia.

There are currently no head-to-head comparisons of Gla300 vs insulin degludec. However, a network meta-analysis comparing Gla-300 to degludec and other basal insulins suggests that Gla-300 exhibits comparable glycemic control, with a significantly lower risk of hypoglycemic events vs $\mathrm{NPH}$, biosimilar glargine, and premixed insulin. ${ }^{47}$ There are very limited patient-oriented outcome data for the effects of Gla-300 on macrovascular or microvascular outcomes, and very limited long-term safety data for the $300 \mathrm{U} / \mathrm{mL}$ insulin glargine strength specifically. Gla-300 has not been studied in patients with insulin resistance (eg, total daily dose exceeding $200 \mathrm{U} / \mathrm{d}$ ). However, currently, for insulin-resistant patients, Gla-300 offers the advantage of providing a higher concentration of basal insulin glargine at one-third the volume of insulin glargine $100 \mathrm{U} / \mathrm{mL}$ (Table 5).

\section{Acknowledgments}

The authors acknowledge Ms Sharon Giovenale and Valori Banfi, University of Connecticut librarians, for their assistance and advice in conducting a thorough literature search.

Table 5 Summary: Gla-300 compared to Gla-100

\begin{tabular}{|c|c|c|}
\hline Insulin & Gla-300 & Gla-I 00 \\
\hline Brand name & Toujeo $^{\circledR}$ & Lantus $^{\circledR}$ \\
\hline Manufacturer & Sanofi-Aventis & Sanofi-Aventis \\
\hline US FDA approval (year) & 2015 & 2000 \\
\hline Vial or pen delivery & Pen & Vial and pen \\
\hline Dosage form & $\begin{array}{l}\text { I.5 mL SoloStar } \\
\text { disposable prefilled } \\
\text { pen (package of } 3 \\
\text { and 5) }\end{array}$ & $\begin{array}{l}\text { - } 10 \mathrm{~mL} \text { vial } \\
\text { - } 3 \mathrm{~mL} \text { SoloStar } \\
\text { prefilled pen } \\
\text { (package of } 5 \text { ) }\end{array}$ \\
\hline $\begin{array}{l}\text { Maximum single dose } \\
\text { delivery of pen (units/dose) }\end{array}$ & 80 & 80 \\
\hline $\begin{array}{l}\text { Expiration in-use } \\
\text { (opened) pen }\end{array}$ & $\begin{array}{l}28 \text { days room } \\
\text { temperature only } \\
\text { (do not refrigerate) }\end{array}$ & $\begin{array}{l}28 \text { days room } \\
\text { temperature only } \\
\text { (do not refrigerate) }\end{array}$ \\
\hline Duration of activity & $>24 \mathrm{~h}$ (up to $36 \mathrm{~h}$ ) & $24 \mathrm{~h}$ \\
\hline \multicolumn{3}{|c|}{ Clinical considerations: Gla-300 vs Gla- 100} \\
\hline Change in $\mathrm{HbA}_{\mathrm{Ic}}$ & \multicolumn{2}{|c|}{ Noninferior } \\
\hline Basal insulin dose & \multicolumn{2}{|c|}{$10 \%-18 \%$ higher dose vs Gla- 100} \\
\hline Body weight & Gla-I00 & ht increase vs \\
\hline Nocturnal hypoglycemia & \multicolumn{2}{|c|}{$\begin{array}{l}21 \%-23 \% \text { reduction only in } \\
\text { insulin-experienced patients with T2DM }\end{array}$} \\
\hline Anytime hypoglycemia & \multicolumn{2}{|l|}{ No difference } \\
\hline
\end{tabular}

Abbreviations: Gla-100, insulin glargine $100 \mathrm{U} / \mathrm{mL}$; Gla-300, insulin glargine $300 \mathrm{U} / \mathrm{mL}$; T2DM, type 2 diabetes mellitus; h, hours.

\section{Author contributions}

This manuscript was conceived, developed, and written by F Wang; S Zassman conducted the literature search and developed the tables; and P A Goldberg critically revised the manuscript. All authors contributed toward data analysis, drafting and critically revising the paper and agree to be accountable for all aspects of the work.

\section{Disclosure}

Dr Goldberg has received speaker honoraria from Novo Nordisk, Eli Lilly, Astra Zeneca, and Boehringer Ingelheim. The authors report no other conflicts of interest in this work.

\section{References}

1. Bolli G, Owens D. Insulin glargine. Lancet. 2000;356(9228):443-445.

2. Riddle MC, Rosenstock J, Gerich J. The treat-to-target trial: randomized addition of glargine or human NPH insulin to oral therapy of type 2 diabetic patients. Diabetes Care. 2003;26(11):3080-3086.

3. Gerstein HC, Bosch J, Dagenais GR, et al. Basal insulin and cardiovascular and other outcomes in dysglycemia. $N$ Engl J Med. 2012;367(4):319-328.

4. Davies M, Lavalle-González F, Storms F, Gomis R. Initiation of insulin glargine therapy in type 2 diabetes subjects suboptimally controlled on oral antidiabetic agents: results from the ATLANTUS trial. Diabetes Obes Metab. 2008;10(5):387-399.

5. Sanofi: Confronting Lantus patent expiry with more efficient successor Toujeo, 2014. Available from: http://seekingalpha.com/article/2395325sanofi-confronting-lantus-patent-expiry-with-more-efficient-successortoujeo. Updated August 7, 2014. Accessed August 10, 2016.

6. U.S. food and drug administration. FDA approves basaglar, the first "follow-on" insulin glargine product to treat diabetes, 2015. Available from: http://www.fda.gov/NewsEvents/Newsroom/PressAnnouncements/ucm477734.htm. Updated December 16, 2015. Accessed August 10, 2016.

7. U.S. FDA news release. FDA approves two new drug treatments for diabetes mellitus, 2015. Available from: http://www.fda.gov/NewsEvents/Newsroom/PressAnnouncements/ucm464321.htm. Updated September 25, 2015. Accessed August 10, 2016.

8. Owens DR, Matfin G, Monnier L. Basal insulin analogues in the management of diabetes mellitus: what progress have we made? Diabetes Metab Res. 2014;30(2):104-119.

9. Monami M, Marchionni N, Mannucci E. Long-acting insulin analogues vs. NPH human insulin in type 1 diabetes. A meta-analysis. Diabetes Obes Metab. 2009;11:372-378.

10. Monami M, Marchionni N, Mannucci E. Long-acting insulin analogues versus NPH human insulin in type 2 diabetes: a meta-analysis. Diabetes Res Clin Pract. 2008;81(2):184-189.

11. Abali S, Turan S, Atay Z, Güran T, Haliloglu B, Bereket A. Higher insulin detemir doses are required for the similar glycemic control: comparison of insulin detemir and glargine in children with type 1 diabetes mellitus. Pediatr Diabetes. 2015;16(5):361-366.

12. Bryant GA, McDanel DL, Horner KE, Farris KB, Newkirk EN. Evaluation of dosing and clinical outcomes in patients undergoing conversion of insulin glargine to insulin detemir. Pharmacotherapy. 2013; 33(1):56-62.

13. Swinnen SG, Simon AC, Holleman F, Hoekstra JB, Devries JH. Insulin detemir versus insulin glargine for type 2 diabetes mellitus. Cochrane Database Syst Rev. 2011;6(7):CD006383.

14. Wallace JP, Wallace JL, McFarland MS. Comparing dosing of basal insulin analogues detemir and glargine: is it really unitper-unit and dose-per-dose? Ann Pharmacother. 2014;48(3): 361-368. 
15. Ashwell SG, Gebbie J, Home PD. Twice-daily compared with once-daily insulin glargine in people with Type 1 diabetes using meal-time insulin aspart. Diabet Med. 2006;23:879-886.

16. Umesh D, Castro E. Insulin U100, 200, 300, or 500? Br J Diabetes. 2016; $16: 10-15$.

17. Jonassen I, Havelund S, Hoeg-Jensen T, Steensgaard DB, Wahlund PO, Ribel U. Design of the novel protraction mechanism of insulin degludec, an ultra-long-acting basal insulin. Pharm Res. 2012;29(8):2104-2114.

18. Heise T, Nosek L, Bøttcher S, Hastrup H, Haahr H. Ultra-long-acting insulin degludec has a flat and stable glucose-lowering effect in type 2 diabetes. Diabetes Obes Metab. 2012;14(10):944-950.

19. Heise T, Hermanski L, Nosek L, Feldman A, Rasmussen S, Haahr $H$. Insulin degludec: four times lower pharmacodynamic variability than insulin glargine under steady-state conditions in type 1 diabetes. Diabetes Obes Metab. 2012;14(9):859-864.

20. European Medicine Agency. Abasaglar: Summary of Product Characteristics; 2014. Available from: http://www.ema.europa.eu/docs/en_GB/ document_library/EPAR_-_Product_Information/. Updated September 9, 2014. Accessed August 10, 2016.

21. Becker RH, Dahmen R, Bergmann K, Lehmann A, Jax T, Heise T. New insulin glargine 300 units $\cdot \mathrm{mL}-1$ provides a more even activity profile and prolonged glycemic control at steady state compared with insulin glargine 100 units · mL-1. Diabetes Care. 2015;38(4):637-643.

22. Jax T, Heise T, Dahmen R, et al. New insulin glargine formulation has a flat and prolonged steady state profile in subjects with type 1 diabetes [abstract]. Diabetologia. 2013;56(Suppl 1):A1029.

23. Riddle MC. Lessons from peglispro: IMAGINE how to improve drug development and affordability. Diabetes Care. 2016;39(4):499-501.

24. Terauchi Y, Koyama M, Cheng X, et al. New insulin glargine $300 \mathrm{U} /$ $\mathrm{mL}$ versus glargine $100 \mathrm{U} / \mathrm{mL}$ in japanese people with type 2 diabetes using basal insulin and oral antihyperglycaemic drugs: glucose control and hypoglycaemia in a randomized controlled trial (EDITION JP 2). Diabetes Obes Metab. 2016;18(4):366-374.

25. Toujeo ${ }^{\circledR}$ (insulin glargine 300 units $/ \mathrm{mL}$ ) [prescribing information]. Bridgewater, NJ: Sanofi-Aventis U.S. LLC; 2015.

26. European Medicines Agency. Toujeo (insulin glargine U300): Summary of product characteristics; 2016. Available from: http://www.ema. europa.eu. Updated February 2015. Accessed July 29, 2016.

27. Wang F, Carabino JM, Vergara CM. Insulin glargine: a systematic review of a long-acting insulin analogue. Clin Ther. 2003;25(6):1541-1577.

28. Bolli GB, DeVries JH. New long-acting insulin analogs: from clamp studies to clinical practice. Diabetes Care. 2015;38(4):541-543.

29. Steinstraesser A, Schmidt R, Bergmann K, Dahmen R, Becker RH. Investigational new insulin glargine $300 \mathrm{U} / \mathrm{mL}$ has the same metabolism as insulin glargine 100 U/mL. Diabetes Obes Metab. 2014;16(9):873-876.

30. Riddle MC, Bolli GB, Ziemen M, Muehlen-Bartmer I, Bizet F, Home PD. New insulin glargine 300 units $/ \mathrm{mL}$ versus glargine 100 units $/ \mathrm{mL}$ in people with type 2 diabetes using basal and mealtime insulin: glucose control and hypoglycemia in a 6-month randomized controlled trial (EDITION 1). Diabetes Care. 2014;37(10):2755-2762.

31. Shiramoto M, Eto T, Irie S, et al. Single-dose new insulin glargine $300 \mathrm{U} / \mathrm{mL}$ provides prolonged, stable glycaemic control in Japanese and European people with type 1 diabetes. Diabetes Obes Metab. 2015;17(3): $254-260$.

32. Tillner JA, Bergmann K, Teichert L, Dahmen R, Heise T, Becker RH. Euglycaemic single dose clamp profile of new insulin glargine formulation in subjects with type 1 diabetes is flat and prolonged [abstract no.1033]. Diabetologia. 2013;56(Suppl 1):S415.

33. Becker RH, Nowotny I, Teichert L, Bergmann K, Kapitza C. Low within- and between-day variability in exposure to new insulin glargine 300 U/mL. Diabetes Obes Metab. 2015;17(3):261-267.

34. Jinnouchi H, Koyama M, Amano A, et al. Continuous glucose monitoring during Basal-Bolus therapy using insulin glargine $300 \mathrm{U} \mathrm{mL}-1$ and glargine $100 \mathrm{U}$ mL-1 in Japanese people with type 1 diabetes mellitus: a crossover pilot study. Diabetes Ther. 2015;6(2):143-152.

35. Monnier L, Owens DR, Bolli GB. The new long-acting insulin glargine U300 achieves an early steady state with low risk of accumulation. Diabetes Metab. 2016;42(2):77-79.
36. Lucidi P, Porcellati F, Rossetti P, et al. Metabolism of insulin glargine after repeated daily subcutaneous injections in subjects with type 2 diabetes. Diabetes Care. 2012;35(12):2647-2649.

37. Yki-Jaervinen $H$, Bergenstal R, Ziemen $M$, et al. New insulin glargine 300 units/mL versus glargine 100 units/mL in people with type 2 diabetes using oral agents and basal insulin: glucose control and hypoglycemia in a 6-month randomized controlled trial (EDITION 2). Diabetes Care. 2014;37:3235-3243.

38. Bolli GB, Riddle MC, Bergenstal RM, et al. New insulin glargine $300 \mathrm{U} / \mathrm{mL}$ compared with glargine $100 \mathrm{U} / \mathrm{mL}$ in insulin-naïve people with type 2 diabetes on oral glucose-lowering drugs: a randomized controlled trial (EDITION 3). Diabetes Obes Metab. 2015;17(4):386-394.

39. Home PD, Bergenstal RM, Bolli GB, et al. New insulin glargine 300 units $/ \mathrm{mL}$ versus glargine 100 units $/ \mathrm{mL}$ in people with type 1 diabetes: a randomized, phase 3a, open-label clinical trial (EDITION 4). Diabetes Care. 2015;38(12):2217-2225.

40. Matsuhisa M, Koyama M, Cheng X, et al. New insulin glargine $300 \mathrm{U} / \mathrm{mL}$ versus glargine $100 \mathrm{U} / \mathrm{mL}$ in Japanese adults with type 1 diabetes using basal and mealtime insulin: glucose control and hypoglycaemia in a randomized controlled trial (EDITION JP 1). Diabetes Obes Metab [EDITION JP 1]. 2016;18(4):375-383.

41. Riddle MC, Yki-Järvinen H, Bolli GB, et al. One-year sustained glycaemic control and less hypoglycaemia with new insulin glargine 300 $\mathrm{U} / \mathrm{mL}$ compared with $100 \mathrm{U} / \mathrm{mL}$ in people with type 2 diabetes using basal plus meal-time insulin: the EDITION 1 12-month randomized trial, including 6-month extension. Diabetes Obes Metab. 2015;17(9): 835-842.

42. Yki-Järvinen H, Bergenstal RM, Bolli GB, et al. Glycaemic control and hypoglycaemia with new insulin glargine $300 \mathrm{U} / \mathrm{mL}$ versus insulin glargine $100 \mathrm{U} / \mathrm{mL}$ in people with type 2 diabetes using basal insulin and oral antihyperglycaemic drugs: the EDITION 2 randomized 12-month trial including 6-month extension. Diabetes Obes Metab. 2015;17(12):1142-1149.

43. Terauchi Y, Koyama M, Cheng X, Sumi M, Hirose T. Sustained glycaemic control and less hypoglycaemia over $1 y$ with new insulin glargine $300 \mathrm{U} / \mathrm{mL}$ vs glargine $100 \mathrm{U} / \mathrm{mL}$ in japanese type 2 diabetes mellitus people on basal insulin + OAD(s) (EDITION JP 2) [abstract no.94-LB]. Diabetes. 2014;63(Suppl 1A):LB24.

44. Matsuhisa M, Koyama M, Cheng X, Sumi M, Hirose T. Sustained glycemic control and less nocturnal hypoglycemia with new insulin glargine $300 \mathrm{U} / \mathrm{mL}$ compared with glargine $100 \mathrm{U} / \mathrm{mL}$ over 12 months in japanese people with T1DM (EDITION JP 1) [abstract no. 987-P]. Diabetes. 2015;64(Suppl 1):A250.

45. Ritzel R, Roussel R, Bolli GB, et al. Patient-level meta-analysis of the EDITION 1, 2 and 3 studies: glycaemic control and hypoglycaemia with new insulin glargine $300 \mathrm{U} / \mathrm{mL}$ versus glargine $100 \mathrm{U} / \mathrm{mL}$ in people with type 2 diabetes. Diabetes Obes Metab. 2015;17(9): 859-867.

46. Ritzel R, Roussel R, Giaccari A, et al. Glycemic control and hypoglycemia with insulin glargine $300 \mathrm{U} / \mathrm{mL}$ (gla-300) vs. gargline $100 \mathrm{U} / \mathrm{mL}$ (gla-100) in type 2 diabetes (T2DM) in a patient-level meta-analysis of 1-yr phase 3a EDITION studies [abstract no. 1030-P]. Diabetes. 2015;64(Suppl 1):A264.

47. Freemantle N, Chou E, Frois C, et al. Safety and efficacy of insulin glargine $300 \mathrm{u} / \mathrm{mL}$ compared with other basal insulin therapies in patients with type 2 diabetes mellitus: a network meta-analysis. BMJ Open. 2016;6(2):e009421. doi:10.1136/bmjopen-2015-009421.

48. Twigg SM, Escalada J, Grisoni M, et al. Age, BMI, and diabetes duration: effect on glycemic control and hypoglycemia with insulin glargine $300 \mathrm{U} / \mathrm{mL}$ in type 2 diabetes (T2DM) [abstract no.1017-P]. Diabetes. 2015;64(Suppl 1):A260.

49. Yale J, Aroda V, Charbonnel B, et al. Older people with type 2 diabetes: glycemic control and hypoglycemia risk with new insulin glargine 300 U/mL [abstract no. 991-P]. Diabetes. 2015;64(Suppl 1):A252.

50. Buzzetti R, Pettus JH, Brito-Sanfiel M, et al. New insulin glargine 300 $\mathrm{U} / \mathrm{mL}$ (gla-300) in combination with dipeptidyl peptidase IV inhibitors in T2DM (EDITION 2 and 3): glycemic control and hypoglycemia [abstract no. 95-LB]. Diabetes. 2015;64(Suppl A1):LB24. 
51. Escalada J, Halimi S, Senior PA, et al. Glycemic control and hypoglycemia benefits with insulin glargine $300 \mathrm{U} / \mathrm{mL}$ (gla-300) extend to people with type 2 diabetes (T2DM) and mild-to-moderate renal impairment [abstract no. 69-OR]. Diabetes. 2016;65(Suppl 1):A18.

52. American diabetes association workgroup on hypoglycemia. Defining and reporting hypoglycemia in diabetes: a report from the american diabetes association workgroup on hypoglycemia. Diabetes care. 2015;28:1245-1249.

53. Reid T, Odugbesan O, Gill J, Nikonova E, Chao J, Bailey TS. Reduced hypoglycemia and comparable efficacy with insulin glargine $300 \mathrm{U} / \mathrm{mL}$ (gla-300) vs. insulin glargine $100 \mathrm{U} / \mathrm{mL}$ (gla-100) in subjects with T2D achieving different levels of prebreakfast SMPG [abstract no. 95-LB]. Diabetes. 2016;65(Suppl 1):A LB25-26.

54. Roussel R, D'Emden MC, Fisher M, et al. Switching from twice-daily basal insulin to once-daily new insulin glargine $300 \mathrm{U} / \mathrm{mL}$ (gla-300): an analysis in people with T2DM (EDITION 1 and 2) [abstract no. 1021-P]. Diabetes. 2015;64(Suppl 1):A261.

55. Riddle MC, Home PD, Avogaro A, et al. A clinically-defined nocturnal window for analysis of hypoglycemia with new insulin glargine 300 $\mathrm{U} / \mathrm{mL}$ in type 2 diabetes (T2DM) [abstract no. 1027-P]. Diabetes. 2015;64(Suppl 1):A263.

56. Bolli GB, Wysham CH, Fisher M, et al. Wider windows for evaluating nocturnal hypoglycemia capture more events and confirm lower nocturnal hypoglycemia risk with insulin glargine $300 \mathrm{U} / \mathrm{mL}$ (gla-300) vs. 100 U/mL (gla-100) in T2DM [abstract no.91-LB]. Diabetes. 2016; 65(Suppl 1):A LB24.

57. Bonadonna RC, Yale J, Brulle-Wohlhueter C, Boelle-Le Corfec E, Choudhary P, Bailey TS. Hypoglycemia as a function of HbAlc in type 2 diabetes (T2DM): insulin glargine $300 \mathrm{U} / \mathrm{mL}$ in a patient-level metaanalysis of EDITION 1,2, and 3 [abstract no.928-P]. Diabetes. 2016; 65(Suppl 1):A239.

58. Rosenstock J, Ritzel RA, Chevalier S, Balkau B, Roussel R. Clinical perspectives from the BEGIN and EDITION longer-acting insulin programs: trial-level meta-analyses outcomes with either degludec (IDeg) or glargine $300 \mathrm{U} / \mathrm{mL}$ (gla-300) vs. glargine $100 \mathrm{U} / \mathrm{mL}$ (gla-100) in T2DM [abstract no. 962-P]. Diabetes. 2016;65(Suppl 1):A249.
59. Stella P, Aroda V, Charbonnel B, et al. Older people with type 2 diabetes: glycaemic control and hypoglycaemia risk with new insulin glargine 300 U/mL (gla-300). Diabetologia. 2015;58(Suppl 1):S473.

60. Riddle MC, Bolli GB, Home PD, et al. Efficacy and safety of flexible versus fixed dosing intervals of insulin glargine $300 \mathrm{u} / \mathrm{mL}$ in people with type 2 diabetes. Diabetes Technol Ther. 2016;18(4): 251-257.

61. Klonoff D, Nayberg I, Thonius M, et al. Accuracy and injection force of the gla-300 injection device compared with other commercialized disposable insulin pens. J Diabetes Sci Technol. 2015;10(1): 125-130.

62. Pohlmeier H, Klonoff DC, Berard L, et al. Ease of use of the new insulin glargine $300 \mathrm{U} / \mathrm{mL}$ solostar pen injector in insulin-naive people with type 2 diabetes [abstract no. 1052-P]. Diabetes. 2015;64(Suppl 1): A269-A270.

63. Klonoff D, Nayberg I, Erbstein F, Cali A, Brulle-Wohlhueter C, Haak T. Usability of the gla-300 injection device compared with three other commercialized disposable insulin pens: results of an interview-based survey. J Diabetes Sci Technol. 2015;9(4):936-938.

64. Ye F, Agarwal R, Kaur A, et al. Real-world assessment of patient characteristics and clinical outcomes of early users of the new insulin glargine 300 U/mL [abstract no. 943-P]. Diabetes. 2016;65(Suppl 1):A243.

65. Meneghini L, Lingvay I, Chao J, Stuhr A, Kazemi M, Dalal M. Efficacy and safety of new insulin glargine $300 \mathrm{units} / \mathrm{mL}$ in insulin-naïve patients with type 2 diabetes mellitus (EDITION 3 ) using selected HEDIS measures [abstract no. THR-660]. Presented at: The Endocrine Society's 97th Annual Meeting \& Expo; March 5; 2015; San Diego, CA.

66. Hood RC, Arakaki RF, Wysham CH, Li Y, Settles JA, Jackson JA. Two treatment approaches for human regular U-500 insulin in patients with type 2 diabetes not achieving adequate glycemic control on highdose U-100 insulin therapy with or without oral agents: a randomized titration-to-target clinical trial. Endocr Pract. 2015;21(7):782-793.

67. Mari A, Rosenstock J, Ma YL, Jackson JA. Optimized human regular U-500 insulin treatment improves beta-cell function in severely insulinresistant patients with long-standing type 2 diabetes and high insulin requirements. Endocr Pract. 2015;21(12):1344-1352.

Diabetes, Metabolic Syndrome and Obesity: Targets and Therapy

Dovepress

\section{Publish your work in this journal}

Diabetes, Metabolic Syndrome and Obesity: Targets and Therapy is an international, peer-reviewed open-access journal committed to the rapid publication of the latest laboratory and clinical findings in the fields of diabetes, metabolic syndrome and obesity research Original research, review, case reports, hypothesis formation, expert opinion and commentaries are all considered for publication. The manuscript management system is completely online and includes a very quick and fair peer-review system, which is all easy to use. Visit http://www.dovepress.com/testimonials.php to read real quotes from published authors. 